\title{
ENFERMEDAD TROFOBLASTICA GESTACIONAL
}

\section{Instituto Materno Infantil - Servicio de Toxemias - Bogotá}

\author{
Dr. Jesús Alberto Gómez-Palacino* \\ Dr. Ricardo Alvarado Pantoja** \\ Dr. Jaime Cantillo G.*** \\ Dra. Harlem de Ruiz*****
}

\section{Introducción}

Bajo la denominación de Enfermedad Trofoblástica se agrupan las neoplasias desarrolladas a expensas de la placenta 0 de las células germinativas de las gónadas de ambos sexos. Ocasionalmente un tumor trofoblástico puede tener su origen en células primordiales desplazadas a distintos órganos. De acuerdo, pues, con su origen y desarrollo, la Enfermedad Trofoblástica puede ser gestacional y no gestacional.

Las neoplasias trofoblásticas iniciadas en el embarazo comprenden la mola hidatiforme, el corioadenoma destruens y el coriocarcinoma, tumores todos caracterizados histológicamente por la proliferación del trofoblasto, de grado variable, y biológicamente por la producción de gonadotropinas. La enfermedad, además, en cualquiera de sus formas puede diseminarse más allá del útero y en tales condiciones se habla de Enfermedad Trofoblástica Metastásica.

El conocimiento de la Enfermedad Trofoblástica se remonta al siglo $\mathrm{VI}$ con Aeitius de Amidas, médico de la corte de Justiniano I, e Hipócrates. En 1751 William Smelie hizo la descripción morfológica más completa. En 1889 Sanger sugirió por vez primera que el tumor derivaba de la decidua del embarazo. Marshand en 1895, demostró que la neoplasia se originaba en las células sincitiotrofoblásticas del epitelio corial, lo cual fue confirmado en 1903 por Teacher quien, además, clasificó los tumores de origen uterino.

La terminología más comunmente utilizada se basa en los estudios de Marshand y Ewing.

A pesar de que el conocimiento del síndrome ha tenido una evolución muy lenta, en los últimos años se han logrado progresos importantes

* Profesor Asociado Obstetricia y Ginecología. U. Nacional.

** Profesor Asistente de Patología. U. Nacional.

*** Profesor Asistente de Patología. U. Nacional.

$* * \star *$ Profesora Asistente de Bioquímica. U. Nacional. 
no solamente en la interpretación de la fisiopatogenia de la enfermedad y de su histopatología sino, principalmente, en cuanto a su manejo terapéutico.

Los aportes de la genética y la inmunología han abierto un amplio campo a la investigación de su génesis y la aplicación de la quimioterapia, a partir de 1956, reduce cada día más las cifras de mortalidad hasta hace poco tiempo muy altas.

El presente estudio pretende reunir los conceptos actuales acerca de la Enfermedad Trofoblástica, así como también presentar nuestra propia experiencia en la investigación y manejo de la compleja entidad.

En Colombia, al igual que en muchos países, la literatura médica relacionada con las neoplasias del trofoblasto es escasa y las publicaciones muy reducidas.

De manera sucesiva presentaremos un análisis de las diferentes modalidades de la enfermedad teniendo como fundamento el estudio continuado, durante 30 meses, de pacientes hospitalizadas en el Servicio de Toxemias del Instituto Materno Infantil de Bogotá, organización dedicada a la atención de una clase socio-económica de escasos recursos y precarias condiciones de salud.

\section{Material y Métodos}

El estudio comprende el análisis de 112 casos de Enfermedad Trofoblástica atendidos en el lapso comprendido entre febrero de 1969 y agosto de 1971. Durante este período ingresaron al Instituto 71.501 pacientes embarazadas, fueron atendidos 54.771 partos, 16.372 abortos y 538 embarazos ectópicos.

\section{MOLA HIDATIFORME}

\section{Definición}

Se caracteriza esta forma de la Enfermedad Trofoblástica por la severa deformación, parcial o total, de las vellosidades coriales a cuyo nivel ocurren tres fenómenos principales: 1 degeneración hidrópica' 2 desintegración de su vasculatura y 3 proliferación trofoblástica de intensidad variable.

\section{Etiopatogenia}

Las siguientes hipótesis etiológicas según Lauslahti (68), se han emitido para explicar la génesis de la mola:

De origen cromosómico:

Bayer (14)

Makino (74)

Bourgoin y col. (20)

Riviere y col. (89)

De origen en los grupos sanguíneos:

Llevelin-Jones (70)

De origen viral:

Edmonds (41)

Ivanov (63)

Thiede y col. (100)

Trastornos de nidación:

Iffi (62)

Proceso inmunológico:

Mathé y col. (76)

Además, Acosta-Sison (2) Márquez Monter (75) y Poen y Djojopranoto (87), han invocado la desnutrición, las bajas condiciones socio-económicas y la tuberculosis como factores involucrados en la etiología.

Iliya, Williamson y Azar (61) atribuyen a la consanguinidad papel importante en la etiología de la mola y el coriocarcinoma. 
Histopatogénesis.

Aspectes genéticos e inmunológicos.

De acuerdo con la hipótesis de Hertig y Edmonds (59) el proceso se inicia con la muerte del embrión junto con la actividad secretora continuada del trofoblasto lo cual ocasiona: a) acumulación de fluídos dentro de las vellosidades puesto que ha desaparecido la circulación embrionaria y b) hiperplasia del trofoblasto "distendido".

Park (86), por el contrario, cree que el fenómeno comienza en el trofoblasto, al cual considera estructural y funcionalmente anormal, lo cual ocasiona absorción excesiva de líquidos al interior de las vellosidades, con la consiguiente destrucción de vasos sanguíneos por la simple presión y la muerte del embrión consecutiva. El siguiente esquema resume las dos hipótesis:

\section{A - Hipótesis de Hertig y Edmonds}

Muerte del embrión<smiles>[3H]C</smiles>

Acumulación de líquidos dentro de las vellosidades

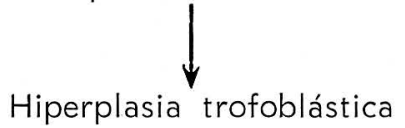

\section{B - Hipótesis de Park}

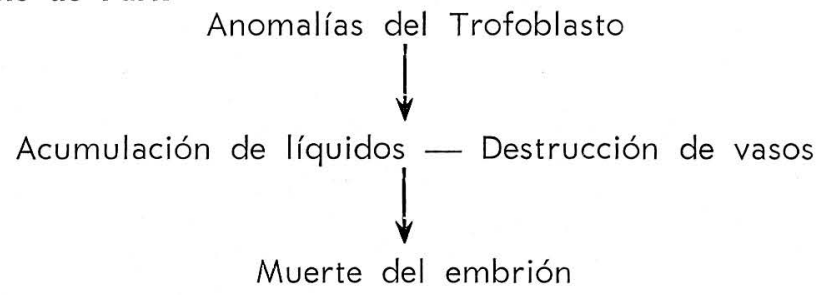

Basado en los estudios de Atkin y Klinger, quienes encontraron cromatina positiva en 47 de 53 molas estudiadas y en 4 de 6 cultivos hallaron un complemento cromosómico femenino, Park concluye que los tejidos de las molas hidatiformes son de ordinario cromatino-positivas y que la mayoría de ellas tienen una constitución cromosómica $\mathrm{XX}$ euploide. La mola, para el citado autor, puede aceptarse como un conceptus femenino y la teoría de la muerte del embrión como fenómeno primario en el desarrollo de la mola podría impugnarse dado que en tal supuesto debe- ría haber un número proporcional de molas cromatina positivas y negativas. Por el contrario, Park (86) piensa que la teoría de la alteración trofoblástica primaria puede ajustarse mejor a las observaciones de Makino y asociados (74) quienes han encontrado aberraciones cromosómicas de grado variable en la mola hidatiforme, el corioadenoma y el coriocarcinoma.

Otro argumento en contra de la muerte del embrión como elemento primario en la formación de la mola sería la presencia de éste en algunos 
casos de la llamada mola embrionada.

Bourgoin y cols. (20) atribuyen la etiología de la mola a trastornos cromosómicos con mitosis aneuploides. Fara Novak y Frankel, citados por Riviere y cols. (89), la mola sería la consecuencia de un defecto en el sistema inmunitario de defensa de la madre incapaz de limitar la invasión de sus tejidos por las metástasis trofoblásticas y de destruirlas.

Eichwald y Silmser (42), encontraron un sistema de histocompatibilidad ligado al sexo y observaron que en cierta especie de ratones la hembra rechazaba siempre el injerto de piel del macho mientras aceptaba el trasplante de hembra a macho, de macho a macho y de hembra a hembra. Hauschka (55) propuso una hipótesis según la cual la hembra recipiente podría formar anticuerpos contra los genes del cromosoma $Y$ resultando una reacción culpable del rechazo.

De acuerdo con los estudios de Tominaga y Page (102) la myaor parte de las molas y corioadenomas son de constitución cromosómica $X X$ surgiendo con ello dos alternativas: a) que el trofoblasto $X X$ sea más susceptible de formar tumores que el $X Y$ y b) que algunos genes del cromosoma $Y$ están inhibidos para la formación de tumor. Estos conceptos no son aplicables' según los autores' para otros neoplasmas y difíciles de sustentar. Restarían dos hipótesis: 1ạ la mayoría de las molas son femeninas en virtud de su constitu. ción $X X$ que favorecería su crecimiento y $2^{a}$. las placentas $X Y$ son abortadas precozmente a causa de la incompatibilidad $Y$. La placenta es un injerto homólogo, tolerado por el huésped durante un período de tiempo gracias a una virtual ausencia de antígenos de histocompatibilidad 0 por falta de poder antigénico de las células trofoblásticas.

\section{Morfología}

El número y tamaño de las vesículas molares puede variar de manera muy apreciable de cientos a miles para el primero y de milímetros a centímetros para el segundo y en cuanto al volumen total puede llegar a varios litros.

Las modificaciones de las vellosidades coriales interesan en mayor o menor grado el sincitio y el citotrofoblasto, la vasculatura del estroma, las células de Hofbauer y los fibroblastos. Las vellosidades en general están aumentadas de tamaño e hidrópicas.

Proliferación, pleomorfismo y anaplasia son las alteraciones del epitelio corial mientras que a nivel del estroma el edema y la desintegración de los vasos es su característica.

\section{Incidencia}

La frecuencia de la mola hidatiforme tiene grandes variaciones de acuerdo con la distribución geográfica y los grupos étnicos y aún dentro del mismo país. Demostración de lo anterior es el siguiente cuadro:

\section{Autor}

Poen y cols. (87)

Wei y Guyang (111)

Acosta-Sison (3)

Márquez-Monter (75)
País

Indonesia

Taiwan

Filipinas

México

\section{Embarazos}

$1 \times 84$

$1 \times 173$

$1 \times 200$

\section{Fartos}

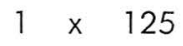


Autor

Haseyawa (54)

Chun (33)

Derek (35)

Fernánidez-Doblado (45)

Brindeau (23)

King (67)

McGregor (72)

Aramburu (9)

Presente Estudio

Cabrera (24)

Fernández (46)

De Snoo (36)

Chesley (32)

Hertig (58)

Novak (82)

\section{Ciudad}

Japón

China

Malasia

México

Francia

China

México

Guatemala

Chile

Brasit

U. S. A.

Holanda

U. S. A.

U. S. A.

\section{Embarazos}

x 232

$\times 242$

$1 \times 290$

$1 \times 400$

$1 \times 500$

$1 \times 530$

$1 \times 613$

$1 \times 670$

$1 \times 680$

$1 \times 829$

$1 \times 1.071$

$1 \times 1.200$
Partos

$1 \times 514$

$1 \times 521$

$1 \times 1.231$

$1 \times 2.000$

$1 \times 2.500$
De acuerdo con la casuística comparada vemos cómo nuestro país ocupa lugar importante en frecuencia de la mola, 3 veces menor que en los países orientales pero 4 mayor que en los Estados Unidos, aproximadamente.

El siguiente cuadro pone de presente la incidencia hospitalaria obtenida en Colombia, de acuerdo con los distintos autores:

\section{Autor}

Valencia y cols. (107)

Acosta-Bendek (1)

Vergara (10)

Duarte (39)

Presente estudio

\section{Ciudad}

Manizales

Barranquilla

Bogotá

Cúcuta

Embarazos
$\begin{array}{ccc}1 & x & 155 \\ 1 & x & 311 \\ 1 & x & 508 \\ 1 & x & 543 \\ 1 & x & 680\end{array}$

\section{Partos}

$\begin{array}{lll}1 & x & 247 \\ 1 & x & 523 \\ 1 & x & 324 \\ 1 & x & 521\end{array}$

Debemos advertir que la enorme frecuencia anotada por Valencia y cols., obedece al criterio diagnóstico diferente por ellos adoptado al considerar como molas las microlesiones edematosas de las vellosidades encontradas en el examen histológico de todos los especímenes abortados, en contraposición al criterio macroscópico seguido por la mayoría de los autores, para quienes el diagnóstico se basa en la observación de las vesículas características a más de los cambios del estroma, del trofoblasto y de los vasos, vistos a través del microscopio.

\section{Clasificación y datos pertinentes}

Basados en el estudio de 200 casos de mola Hertig y Sheldon (60) establecieron en 1947 la correlación histológica con el cuadro clínico y su pronóstico y enunciaron su clasificación inicial en 6 grupos, reducida luego a 3 por el mismo autor y Mansell (58). Para establecer tales grupos se tuvieron en cuenta los siguientes elementos histopatológicos: grado de proliferación, pleomorfismo y anaplasia del trofoblasto, preservación de la membrana basal y compromiso vascular. 
En 1954 Novak (81), insistió en su punto de vista, expresado años atrás, de negar valor a la clasificación histológica por la dificultad en la determinación del grado de anaplasia trofoblástica ya que también en las células trofoblásticas jóvenes normales se presentan grandes variaciones de tamaño, picnosis y cariorrexis.

Otros autores; Hunt, Smalbraak, Shiffer, Douglas, Tow y Yung, han intentado otras clasificaciones no obstante lo cual la de Hertig y Mansell subsiste.

Bur y cols. (21) introdujeron en el análisis del grado de malignización de la mola, por medio de estudios histoquímicos, el aumento de la ba- sofilia nuclear ribonucleasa resistente.

Siguiendo el criterio de clasificación de Hertig y Mansell nuestro estudio arrojó los siguientes resultados:

\begin{tabular}{lcl}
\hline Grado & Casos & $\%$ \\
\hline 1 & 41 & 39 \\
II & 42 & 40 \\
111 & 14 & 13,3 \\
\hline
\end{tabular}

Las microfotografías 1, 2 y 3 muestran las diferencias histopatológicas de los distintos grados.

Hubo además 8 casos de corioadenoma $(7,6 \%)$ que sumados a los anteriores dan un total de 105 molas.

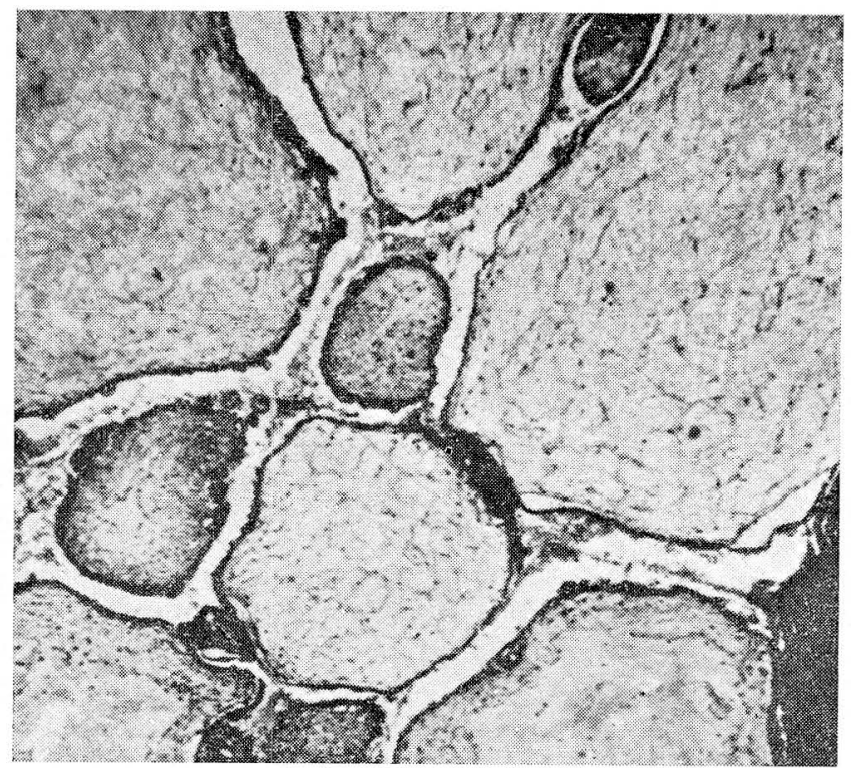

FIGURA 1 - Degeneración hidrópica de una vellosidad corial con escasa proliferación trofoblástica. 


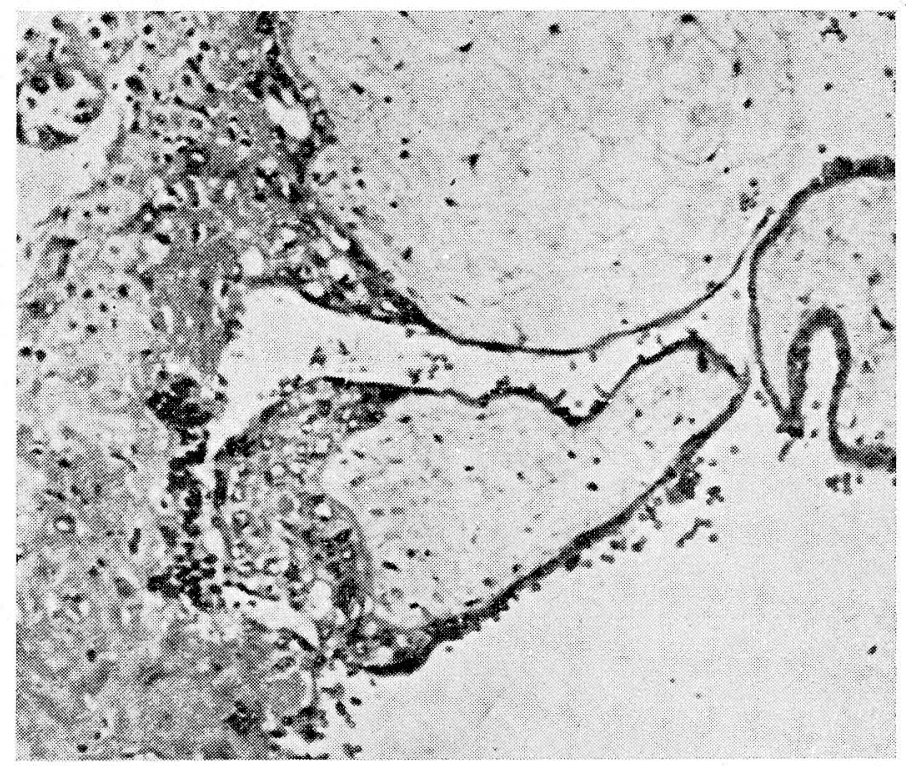

FIGURA 2 - Se observan brotes de proliferación trofoblástica con cierto grado de anaplasia.

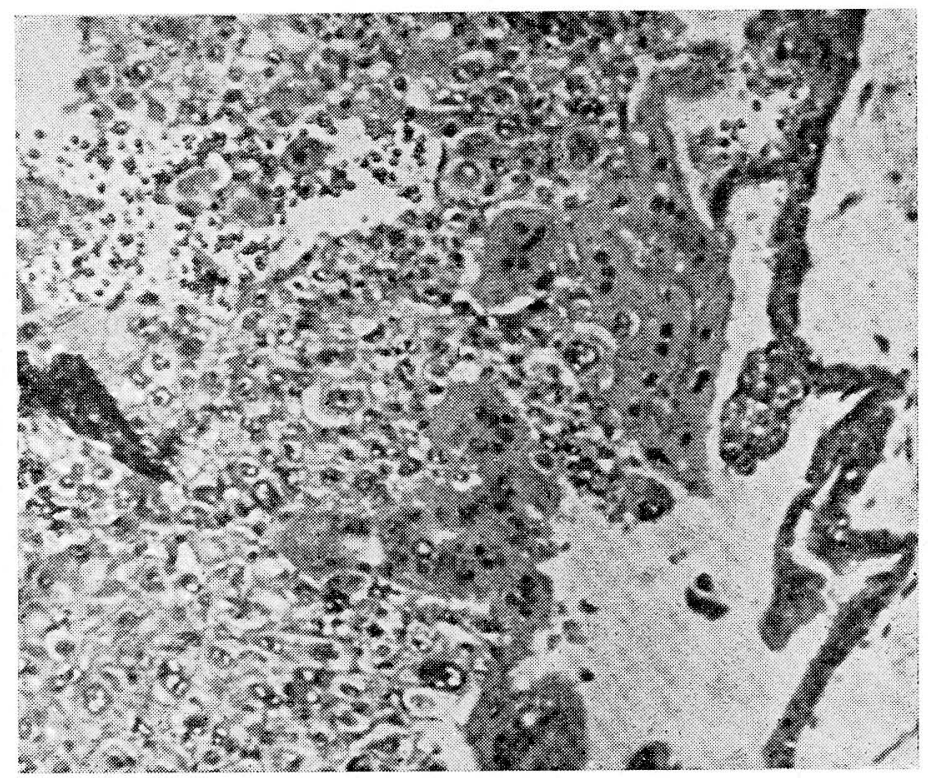

FIGURA 3 - Se observa vellosidad hidrópica con severa proliferación, pleoformismo y anaplasia del trofoblasto. 


\begin{tabular}{lcccc}
\hline Grado & Hertig y Sheldon & Hunt $\mathbf{y}$ col. & Tow y Yung & Presente Estudio \\
\hline II & $11 \%$ & $25 \%$ & $5 \%$ & $39 \%$ \\
II & $61 \%$ & $55 \%$ & $58 \%$ & $40 \%$ \\
III & $28 \%$ & $20 \%$ & $37 \%$ & $13,3 \%$ \\
Invasiva & & & & $7,6 \%$ \\
\hline
\end{tabular}

El anterior cuadro comparativo muestra algunas estadísticas:

Quizá las diferencias estadísticas haladas, según los distintos autores, encuentren explicación en el criterio un tanto subjetivo de los patólogos.

\section{Hechos clínicos}

La mola hidatiforme es más común en mujeres de 20 a 30 años, edad en la cual ocurre el mayor número de embarazos. El siguiente cuadro muestra nuestros hallazgos:

DISTRIBUCION DE LAS MOLAS SEGUN LA EDAD

\begin{tabular}{lccccc}
\hline Edad & Grado I & Grado II & Grado III & Corioadenoma & Total \\
\hline $16-20$ & 11 & 6 & 3 & & 20 \\
$21-25$ & 11 & 13 & 4 & 2 & 30 \\
$26-30$ & 10 & 7 & 1 & 1 & 18 \\
$31-35$ & 2 & 7 & 1 & 1 & 10 \\
$36-40$ & 4 & 1 & 3 & 2 & 7 \\
$41-45$ & 3 & 1 & 2 & 2 & 11 \\
$46-50$ & & 1 & 2 & & 3 \\
$51-$ más & & & & & \\
\hline
\end{tabular}

Nótese como a medida que aumentó la edad fué más severa histológicamente la enfermedad. Hubo 3 pacientes de 16 años y 2 de 52 siendo éstas las edades extremas. Vale la pena mencionar el número alto, 23 casos, o $21,9 \%$ de pacientes por encima de los 40 años, al respecto se ha aducido como explicación la senescencia, involución o lentificación de los procesos íntimos de las células germinativas.

Divack, citado por McGregor y cols. (72) analizando la frecuencia de embarazo molar después de los 50 años en Estados Unidos encontró una incidencia de 1 mola por cada 384 partos; es decir 5 veces mayor a la frecuencia general de la mola en tal país.
A pesar de que la revisión bibliográfica sobre el tema no aporta datos concernientes, hemos creído interesante, teniendo en consideración los aspectos genéticos a nivel cromosómico de la enfermedad, reseñar la edad de los cónyuges, habiendo encontrado 20 casos de esposos de 46 años o más, de los cuales hubo algunos de 60, 62, 70 y 74 años.

El mayor número de molas, 21,9\% de casos, ocurrió en nulíparas, cifra exactamente igual a la informada por Baja-Panlilio (11) de Manila, en su estudio sobre 580 casos.

Adviértase cómo la severidad de los cuadros histológicos fue encontrada, al parecer, independiente del número de gestaciones 0 de la paridad. 


\section{DISTRIBUCION DE LAS MOLAS SEGUN EL No DE PARTOS}

\begin{tabular}{lrrrcr}
\hline & I & II & III & Corioadenoma & Total \\
\hline Nulíparas & 10 & 10 & 2 & 1 & 23 \\
II & 7 & 4 & 3 & & 14 \\
II & 7 & 4 & & 2 & 11 \\
III & 3 & 4 & 1 & 1 & 10 \\
IV & 3 & 5 & 2 & 3 & 11 \\
V & 2 & 7 & 1 & & 13 \\
VI & 2 & 2 & 1 & 1 & 2 \\
VII & 7 & 1 & 1 & & 17 \\
VIII & & 5 & 4 & & \\
O más & & & & & \\
\hline
\end{tabular}

La paciente con mayor número de gestaciones alcanzó a 16 con 13 partos y 2 abortos previos a la mola.

\section{Signos y síntomas}

1. Hemorragia. Con excepción de 3, el resto, 102 pacientes, tuvieron hemorragia genital de intensidad variable pero generalmente prolongada; en 25 casos sobrepasó de un mes, llegando en dos casos hasta 4 meses. En ocasiones no estuvo precedida de amenorrea y generalmente se inició en las primeras 4 a 6 semanas de la gestación.

2. Dolor. Hubo 70 casos, 66,6\%, en los cuales estuvo ausente el dolor antes de la iniciación del aborto. Consideramos que este detalle negativo debe interpretarse como de valor diagnóstico cuando concurre con la hemorragia genital.

3. Toxemia. La concomitancia de toxemia con la mola hidatiforme ha sido referida por distintos autores. Crowel (29) la informa en $26.7 \%$ de los casos. Chesley y col. (32) recolectaron 36 casos de toxemia, incluyendo uno de eclampsia, en pacientes con mola hidatiforme y $14 \%$ de mortalidad. Dieckman (37) encontró 3 casos entre 30 de mola.

La mayoría de los autores anotan que la toxemia ocurre cuando el ta- maño del útero alcanza o sobrepasa la altura del ombligo. Acosta-Sison (4) opina que la hipertensión arterial en la mola resulta de la combinación de 2 factores: el elevado título de las gonadotropinas y el aumento de la presión abdominal a expensas de la sobredistensión del útero. Por otra parte Alvarez (7) estudiando microscópicamente el material placentario obtenido por punción transabdominal en pacientes con toxemia gravídica establece la relación entre la proliferación del trofoblasto y el grado de hipertensión arterial.

Es posible, como lo sugirió Page (84) que el rápido crecimiento de las vellosidades coriales en la mola hidatiforme, se acompañe de isquemia con la subsiguiente formación de elementos vasopresores. Nosotros encontramos 35 casos, $33 \%$, de toxemia asociada a la mola hidatiforme con la siguiente distribución según las formas histológicas:

\section{TOXEMIA $Y$ MOLAS}

\begin{tabular}{lcc}
\hline Grado & Casos & $\%$ \\
\hline I & 12 & 29 \\
II & 14 & 33 \\
III & 5 & 35 \\
Corioadenoma & 4 & 50 \\
\hline
\end{tabular}

Es importante anotar cómo a medida que aumentó la severidad de la 
lesión histológica: proliferación, pleomorfismo, anaplasia y penetración, aumentó la frecuencia de la toxemia. Hubo un caso de Eclampsia en una paciente G15 P11 A3, de 41 años y embarazo de 5 meses. La altura uterina parecía de 30 semanas. El estudio histológico de la mola demostró ser de grado II.

4. Crecimiento uterino. En 87 casos, $82,8 \%$, el útero estaba desproporcionadamente aumentado de tamaño en relación con la amenorrea; en $14,-13,3 \%$, el tamaño era inferior y en 4, - 3,8\%, había correlación. Hubo 3 casos en los cuales, a pesar de que el tamaño uterino era inferior al correspondiente a la edad gestacional' sobrevino la toxemia.

5. Hiperemesis. Solamente ocurrió en 9 casos, $8,04 \%$, de los cuales 2 correspondieron a molas histológicamente grado I, 6 de grado II y una de grado III. El limitado número de casos en donde estuvo presente este signo le resta significación clínica.

\section{Eretismo cardíaco. - Taquicardia.} Manifestaciones cardíacas expresadas por eretismo cardiovascular y taquiesfigmia se presentaron en 33 pacientes, $30 \%$, de las cuales en 9 se trataba de molas grado I, 17 de grado II, 3 de grado III y 4 de corioadenoma.

No hemos encontrado referencias bibliográficas respecto a estos signos clínicos que nosotros consideramos no solamente importantes en cuanto a su frecuencia sino en su relación clínico-patológica, pues al paso que estuvieron presentes en $21,9 \%$ de las molas grado I, se hallaron en el $50 \%$ de los corioadenomas.

En dos ocasiones sobrevino la insuficiencia cardíaca aguda que impuso la digitalización inmediata.
Queriendo dar una explicación fisiopatogénica a estas manifestaciones creemos pertinente mencionar la concomitancia primeramente observada por Tisne y cols. (101) de tirotoxicosis en pacientes con neoplasias trofoblásticas a partir de la cual recientemente dieron justificación Hershman y Higgins (56) con el aislamiento de una substancia LATS (Long Acting Thyroid Stimulator), tirotropina molar que ahora se reconoce como un anticuerpo IgG., diferente inmunológica y químicamente de la tirotropina pituitaria y de la coriónica normal aislada por el mismo Hershman y Starners (57). Dado que solamente en una paciente con metástasis trofoblástica al pulmón se observaron los signos cardiovasculares mencionados, sin otra patología diferente, creemos que constituyen un signo clínico valioso probablemente relacionado con la disfunción tiroidiana.

\section{Quistes ováricos y mola}

El cuadro siguiente muestra la distribución de 45 casos $(42,8 \%$ ) de patología ovárica acompañando la mola hidatiforme:

QUISTES OVARICOS Y MOLA

\begin{tabular}{lcl}
\hline Grado & Casos & $\%$ \\
\hline I & 16 & 39 \\
II & 19 & 45 \\
III & 6 & 42,8 \\
Corioadenoma & 4 & 50 \\
\hline
\end{tabular}

Los hallazgos anotados son apenas sugestivos respecto a su significación clínica. Las estadísticas son muy variables y así mientras Vargas López y cols. ( 109) dan una incidencia de $4,82 \%$, otros la encuentran elevada. Creemos que las diferencias registradas por distintos autores se explican en consideración al momento en el cual se hace la evaluación clínica; 
nosotros hemos observado el mayor número de quistes evacuada la mola y aún varios días después. Es posible, entonces, que los quistes se hagan aparentes por crecimiento súbito luego de la expulsión o extracción del tumor trofoblástico.

Se discute aún su patogenia, aún cuando existe la idea de que su presencia se explica por la estimulación que las gonadotropinas coriales hacen a la hipófisis y la subsiguiente liberación de hormona LH capaz de producir la hiperreactio-luteinalis. Su involución suele ser lenta y de nuestra casuística se anota que no hubo ninguna complicación que impusiera la resolución quirúrgica pese a que algunos quistes alcanzaron tamaños considerables.

\section{Metástasis}

Se observaron metástasis a los pul. mones en 4 casos, de los cuales dos correspondieron a molas grado i y dos a grado II. Sus imágenes fueron interpretadas como procesos bronconeumónicos difusos. Su desaparición se notó en la primera semana que siguió al tratamiento de la mola.

Una paciente de 31 años G8 P7, con mola grado II en útero, presentó metástasis en la vagina y una enferma de 16 años, nulípara, tuvo mola yrado 111 en útero y vagina.

\section{Diagnóstico}

Pese a que en ciertas circunstancias el diaynóstico clínico de la mola hidatifo'me no ofrece dificultades, sobre todu cuando está en evolución el aborto y la simple observación permite apreciar la masa molar, en otras se torna difícil, principalmente en aquellos casos en donde la desproporción entre el tamaño uterino y la amenorrea no existe. Es por ello que en la actualidad se apela a diversos procedimientos tales como:

1. Determinación de las gonadotropinas coriónicas. A más de su valor diagnóstico aqquiere importancia en el control ulterior de la enfermedad. Debe, sin embargo, tenerse en cuenta que altos niveles de eliminación gonadotrópica se pueden encontrar según Alter y Cosgrove (6) y Fox y Tow (47) en embarazos no molares y principalmente entre los días 40 a 80 de la gestación. Para Schelpert (92), las titulaciones de HCG se hacen negativas ordinariamente en las primeras semanas que siguen a la evacuación de la mo!a.

2. El examen radiográfico simple del abdomen en los casos de mola permite apreciar la ausencia de imágenes óseas fetales a menos que se crate de los raros casos de mola embrionada; pierde su valor en embarazos de menos de 16 semanas cuando los puntos de osificación de un embarazo normal también están au. sentes. Por ello, basados en experiencias anteriores Bayan y Apelo (13) introdujeron el histerograma, procedimiento mal denominado también amniografía, que permite observar la imagen típica de las vesículas molares y practicado por rivsotros en 15 casos $(14,2 \%)$ con resultados siempre confirmatorios de la sospecha clínica. Hecha la punción transabdominal con aguja de punción lumbar, previo cateterismo vesical, en el sitio más prominente de la eminencia uterina y una vez descartada la emisión de líquido a través de la aguja, se inyectan 20 a $30 \mathrm{cc}$. de Hyaque e inmediatamente se toma radiografía, que en caso positivo muestra la imagen "en panal" propia de la degeneración molar' tal como se observa en la fotografía № 4. 


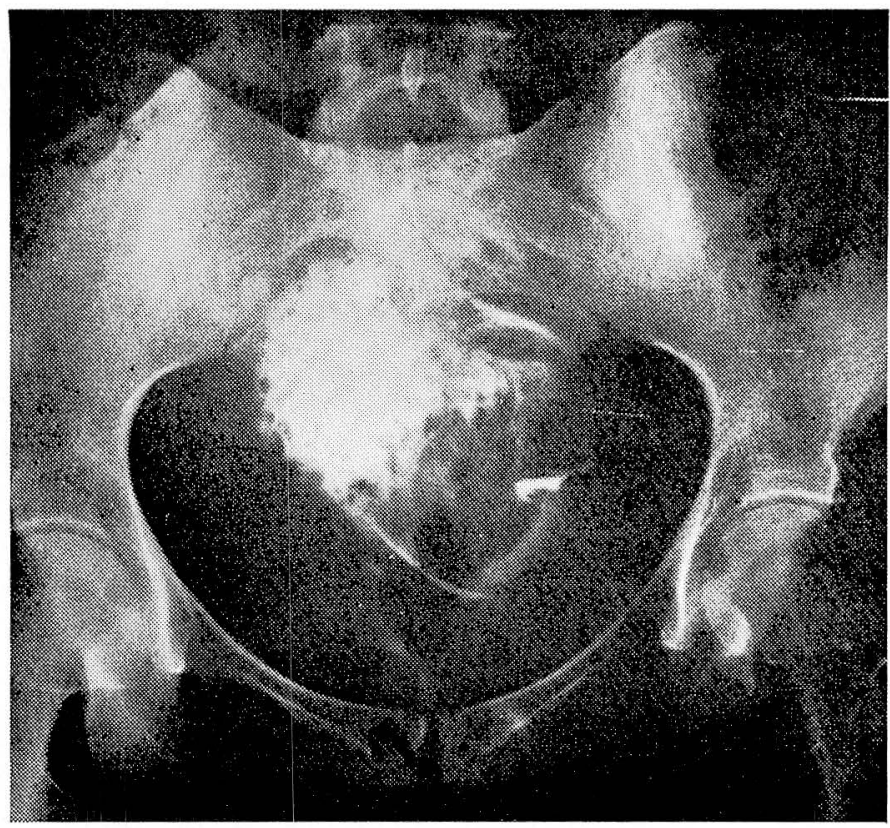

FOTOGRAFIA No 4

3. Harper y McVicar (53) y Gottesfeld (52) han descrito el empleo del ultra-sonido mediante el sistema Dopler en el diagnóstico de la Enfermedad Trofoblástica. Boog y cols. (18) informan su experiencia en 5 casos de mola hidatiforme y concluyen que se trata de un procedimiento fiel e inofensivo.

4. La biopsia placentaria mediante la punción ha sido propuesta por Alvarez (8) con el fin de observar los cambios vellositarios microscópicamente por contraste de fases.

5. La titulación de hormona lactogenoplacentaria (HPL) preconizada por Cohen y cols. (28) y los estudios químicos: elevación de leucina aminopeptidasas del embarazo, Smtih y Rutemburg (97) y las determinaciones de oxitosinasa sérica, Babuna y cols. (10), han sido también empleadas.

De nuestra casuística el diagnóstico fue correcto en 72 casos $(68,5 \%)$ y equivocado en $33(31,4 \%)$. Amenorrea, hemorragia, desproporción altura uterina/amenorrea, los signos de toxemia precoz y de hipertiroidismo, las titulaciones de gonadotropinas $y$ los estudios radiográficos por histerografía fueron los elementos que permitieron el diagnóstico acertado.

Un caso fue equivocadamente interpretado como placenta previa; la confusión diagnóstica más frecuente fue con el aborto no molar.

\section{Tratamiento}

Para el manejo de la enfermedad molar se practicaron las siguientes intervenciones: 
Raspado

Dilatación y Raspado

Histerotomía

Histerectomía

Histerectomía y salpingooforectomía

Se hicieron 15 inducciones del aborto molar utilizando el procedimiento hormonal en 8 casos y la combinación con el de Aburel en 7. Habiendo fracasado en 8 casos de inducciones repetidas se procedió a la dilatación cervical y la evacuación instrumental bajo anestesia peridural. En 3 casos éste fue el procedimiento único.

Una histerotomía fue practicada por error diagnóstico.

El tratamiento complementario con quimioterapia (MTX) fue utilizado en 34 oportunidades así:

Mola grado II

Mola grado III

Corioadenoma

19 Casos

10 "

Un grupo de pacientes, 27 casos' integrado por 23 de grado II y 4 de grado III, no recibió quimioterapia y sirvió de "grupo control". Ninguna paciente cuya mola fue clasificada histológicamente en el grupo I recibió methotrexate.

A la mayoría de las pacientes se les administraron 20 miligramos de MTX diariamente durante 5 días y en 4 ocasiones el medicamento se dio a la manera propuesta por Carcassone y cols. (25), es decir, 5 mlgr. por día durante 20 días.

Se practicaron 19 histerectomías en pacientes cuya lesión trofoblástica fue informada como sigue:

\footnotetext{
Mola grado 1

Moa grado 11

Mola grado III

Corioadenoma
}

2 Casos

6 "

6 "

Hubo 3 casos de corioadenoma tratados exclusivamente con MTX en consideración a la edad de las pa- cientes; de las 5 a quienes se practicó histerectomía en 2 se había llegado previamente al diagnóstico con el raspado y en las 3 restantes la cirugía fue el primer paso del tratamiento.

\section{Controles}

Con excepción de un caso, correspondiente a una mola grado I que no asistió a los controles y de 3 que solamente lo hicieron durante un mes, 101 pacientes tuvieron control adecuado durante varios meses y algunas de ellas 2 años o más.

Los controles incluyeron exámenes clínicos, biológicos y radiológicos.

Fué recomendada la anticoncepción durante un año y para tal efecto se utilizó el dispositivo intrauterino en 80 pacientes; otras han utilizado diversos procedimientos a excepción de las combinaciones hormonales; algunas rechazaron cualquier sistema contraceptivo.

\section{Evolución}

\section{A - Malignización}

Un caso previamente clasificado como endometritis sincitial, 2 molas grado II y una grado III evolucionaron hacia corioadenoma destruens $y$ 3 molas de grado 11 degeneraron en coriocarcinomas.

Ninguna de las 7 pacientes, 25,9\%, que evolucionaron hacia la malignización había recibido previamente quimioterapia; pertenecían al grupo control.

El grupo de pacientes con mola histológicamente grado I no recibió MTX; ninguna sufrió malignización.

Según Hertig y Mansell (58), la proporción de malignización de las molas es de 1 a $2 \%$. Sin embargo Acosta-Sison (2) Baja-Panlilio y Apelo (12), encuentran una frecuencia 
de degeneración de 13 a 17\% en los países orientales. Tow (103) correlaciona el riesgo de malignización con la edad y la paridad de las enfermas, advirtiendo que esa posibilidad es mayor en pacientes de más de 40 años y principalmente en multíparas. Para Morrison (78) la malignización es más frecuente en mujeres con mola recurrente.

\section{B - Embarazos posteriores}

11 pacientes, 0,9\%, quedaron embarazadas posteriormente. Hubo 2 abortos, uno en paciente con dispositivo intrauterino $y$ otro en enferma que había recibido MTX. Ocurrieron 6 partos, uno de ellos gemelar' con hijos normales habiendo recibido methotrexate una de las pacientes antes del embarazo. Tres pacientes se encuentran actualmente en control prenatal.

\section{Formas atípicas}

1. Mola y cáncer de cuello uterino.

G13 P11 A1, 45 años, mola grado 11. Se practicó histerectomía abdominal. El estudio anatomopatclógico reveló cáncer infiltrante de cérvix. Ha sido tratada con Radium y cobaltoterapia. Sobrevive después de $2 \frac{1}{2}$ años de intervenida.

2. G8 P7, 31 años, mola grado II con metástasis en vagina. Tratada con MTX. Actualmente en buenas condiciones.

3. G1 P0, 16 años. Mola grado III con metástasis en la vagina. Tratada con MTX. Desaparición de las metástasis. Actualmente bien.

4. G1, 22 años, mola II; metástasis a pulmones.

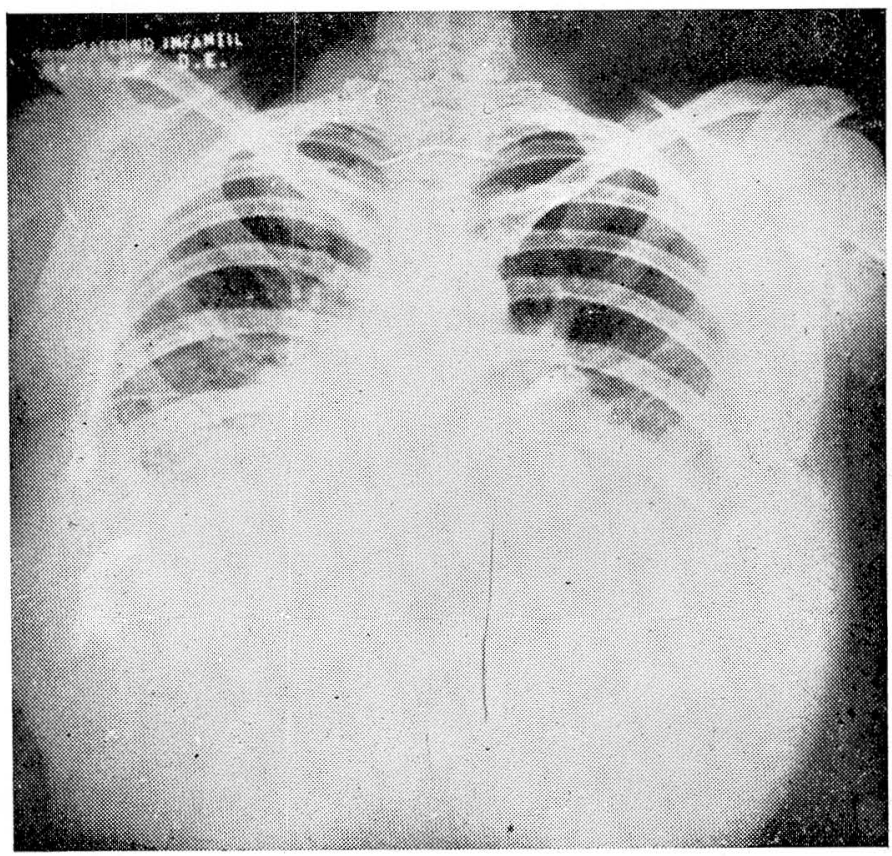

FOTOGRAFIA № 5 
G2 P1, 25 años, mola I; metástasis a pulmones.

G1, 21 años, mola I; metástasis a pulmones.

G8 P7, 25 años, mola II; metástasis a pulmones.

La presencia de tejido trofoblástico no neoplásico y de vellosidades normales en los pulmones ha sido admitida, según Ober (83), como un hecho fisiológico a partir de su penetración en el músculo uterino y en las venas maternas. Metástasis benignas de molas, principalmente a los pulmones y la vagina, han sido informados por Meyer, Novack y Seah (81) entre otros.

En su estudio sobre 189 pacientes de embarazo molar, Goldstein (50) encontró 4 enfermas que hicieron embolia trofoblástica a los pulmones. La imagen radiográfica se caracteriza, tal como se observa en la fotografía № 5, por infiltrados broncoalveolares difusos cuya regresión suele hacerse de manera espontánea una vez evacuada la mola.

5. G2 P1, 24 años, mola transicional.

Hertig y Edmonds (59) son de opinión de que los cambios en esta modalidad de la enfermedad trofoblástica son visibles aún sin la macroscopía pero que el feto o partes del huevo están incluídos y que el cuadro histológico está íntimamente ligado a la verdadera mola.

Con fines estadísticos hemos incluído el presente caso dentro del grupo de las molas grado I. El tratamiento se limitó al raspado uterino.

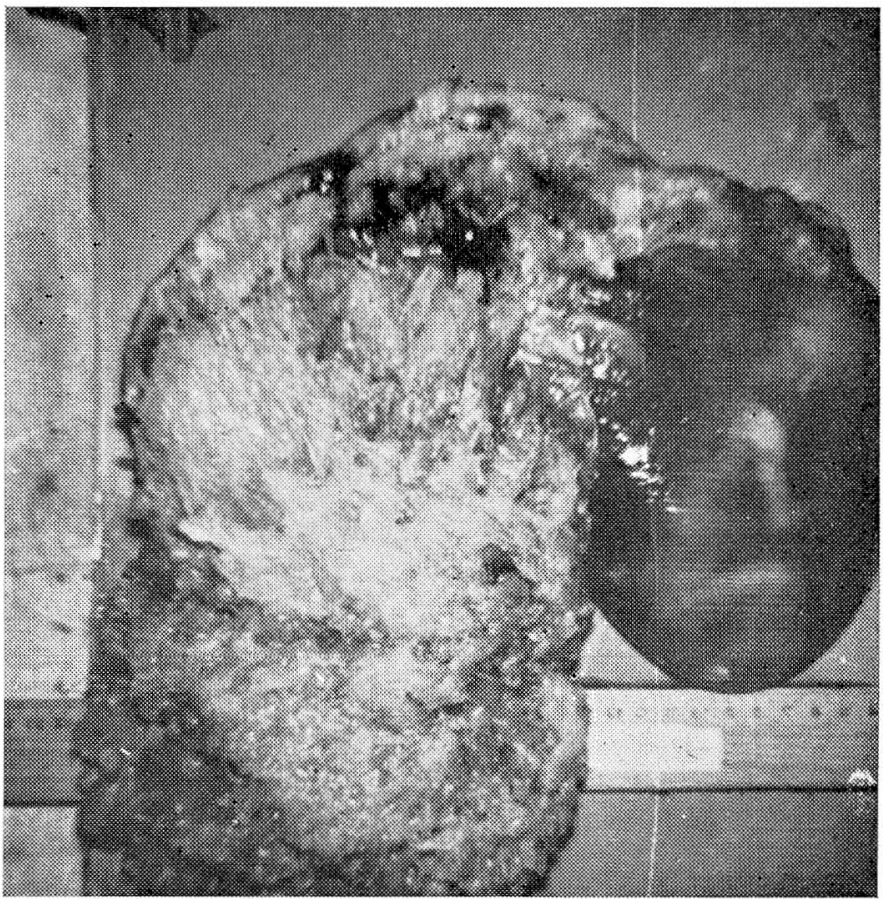

FOTOGRAFIA No 6 
6. G15 P11 A3, 41 años. Eclampsia. Fue tratada con sulfato de magnesia a la manera preconizada por Zuspan (114) y posteriormente sometida a evacuación instrumental de la mola.

7. G7 P5 A1, 33 años. Embarazo gemelar con un huevo normal y otro con degeneración molar grado II. Gestación de 4 meses. Fué tratada con histerectomía.

La posibilidad de embarazo molar con persistencia del feto es, al decir de Beischer y Fortune (17) de 0,6\%. Estos casos ocurren generalmente en embarazos gemelares monozigóticos con degeneración parcial o difusa de la placenta, o lo que es más excepcional, en embarazos gemelares dizigóticos como el que relatamos. En 1960 Sitaratna y Sarma (96) informaron un caso similar con feto viable, completando así el 5\% referido en la bibliografía mundial pues antes $\mathrm{Fa}$ - vreau y Belanger (44) Waters y Cruden (108) Rose (90) y Taylor (99) habían descrito fenómenos similares.

Del caso que informamos, fotografía № 6, el diagnóstico acertado previo a la histerectomía, que fue practicada porque sobrevino hemorragia profusa, había sido hecho clínicamente en consideración al crecimiento desmesurado del útero, la taquicardia, la toxemia precoz y la persistente hemorragia. Al intentar la histerografía el paso de la aguja de punción dio salida a líquido amniótico prescindiéndose en dicho momento de la radiografía pero afirmándose la sospecha clínica de embarazo molar con persistencia fetal.

\section{CORIOADENOMA DESTRUENS}

Aún cuando en la casuística general de la mola hidatiforme hemos incluído esta forma de la Enfermedad Trofoblástica, queremos hacer algunas consideraciones específicas.

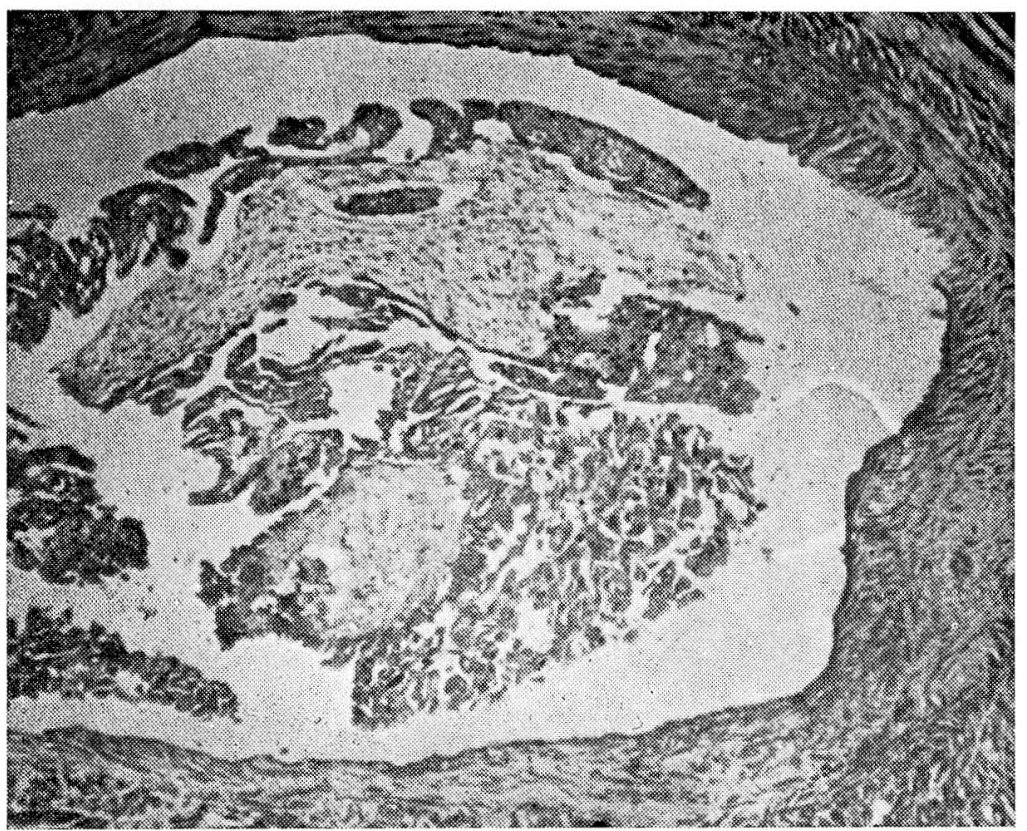

FOTOGRAFIA № 7 


\section{Definición}

Con el término inapropiado de corioadenoma destruens, sugerido por Ewing en 1910 y también denominado mola invasiva, penetrante 0 destructiva, se conoce esta neoplasia caracterizada histológicamente por la presencia de vellosidades coriales con alteración trofoblástica en el interior del miometrio y/o de sus vasos; así se observa en la microfotografía № 7.

A pesar de que generalmente se le considera como una forma benigna de la Enfermedad Trofoblástica, el hecho de que dé lugar a complicaciones tales como la perforación uterina, hemorragias profusas y sepsis, así como también la posibilidad de dar metástasis a pulmón, vagina etc., y que según Greene (49) la mortalidad llegue a $14 \%$ hace dudoso el carácter de benigno que se le ha conferido al corioadenoma.

Para Tow (104) el corioadenoma, considerada su malignidad, debe ser admitido como un coriocarcinoma en el cual la estructura de las vellosidades se ha conservado.

Nuestra experiencia se concreta al estudio de 8 casos cuya distribución por edades y número de gestaciones se detalla en el siguiente cuadro:

\section{CORIOADENOMA}

\begin{tabular}{lll}
\hline Caso & Edad & Gestación \\
\hline 1 & 23 & G5 P2 A2 \\
2 & 24 & G4 P3 \\
3 & 35 & G1 \\
4 & 38 & G6 P4 A1 \\
5 & 42 & G6 P5 \\
6 & 45 & G1 P P10 \\
7 & 50 & G4 P3 \\
8 & 50 & G6 P5 \\
\hline
\end{tabular}

Los datos anteriores nos permiten hacer las siguientes observaciones:
1: Con excepción de un caso, todas las pacientes eran multigestantes.

2. 4 pacientes sobrepasaban los 40 años y de 6 enfermas de 50 o más años con Enfermedad Trofoblástica, 2 tuvieron corioadenoma.

Los siguientes fueron los tratamientos practicados:

\begin{tabular}{|c|c|c|c|}
\hline Caso & Edad & Gestación & Tratamiento \\
\hline 1 & 23 & G5 P2 A2 & Hist. + MTX \\
\hline 2 & 24 & G4 P3 & MTX \\
\hline 3 & 35 & G1 & MTX \\
\hline 4 & 33 & G6 P4 Al & MTX \\
\hline 5 & 42 & G6 P5 & Hist. + MTX \\
\hline 6 & 45 & G11 P10 & Hist. + MTX \\
\hline 7 & 50 & G4 P3 & Hist. + MTX \\
\hline 8 & 50 & G6 P5 & Hist. \\
\hline
\end{tabular}

Cinco pacientes fueron sometidas a histerectomía, una de ellas de 23 años por hemorragia incontrolable después de 4 raspados uterinos, examen histopatológico inicial de coriocarcinoma y radiográfico compatible.

A cuatro de las pacientes histerectomizadas se adicionó la quimioterapia.

Tres pacientes fueron tratadas exclusivamente con methotrexate.

A diferencia de lo observado en los casos de mola grado I, II o III, la negativización de las reacciones biológicas fue más lenta, 2, 4, 5 y 5 meses en 4 casos' independientemente clel tratamiento adoptado pues en uno de ellos había sido la quimioterapia y en 3 la cirugía complementada con methotrexate.

Tres casos estuvieron precedidos, uno de endometritis sincitial, uno de mola grado II y uno de mola III. Ninguno había recibido quimioterapia profiláctica. Cuatro pacientes tenían quistes ováricos pero solamente en el 


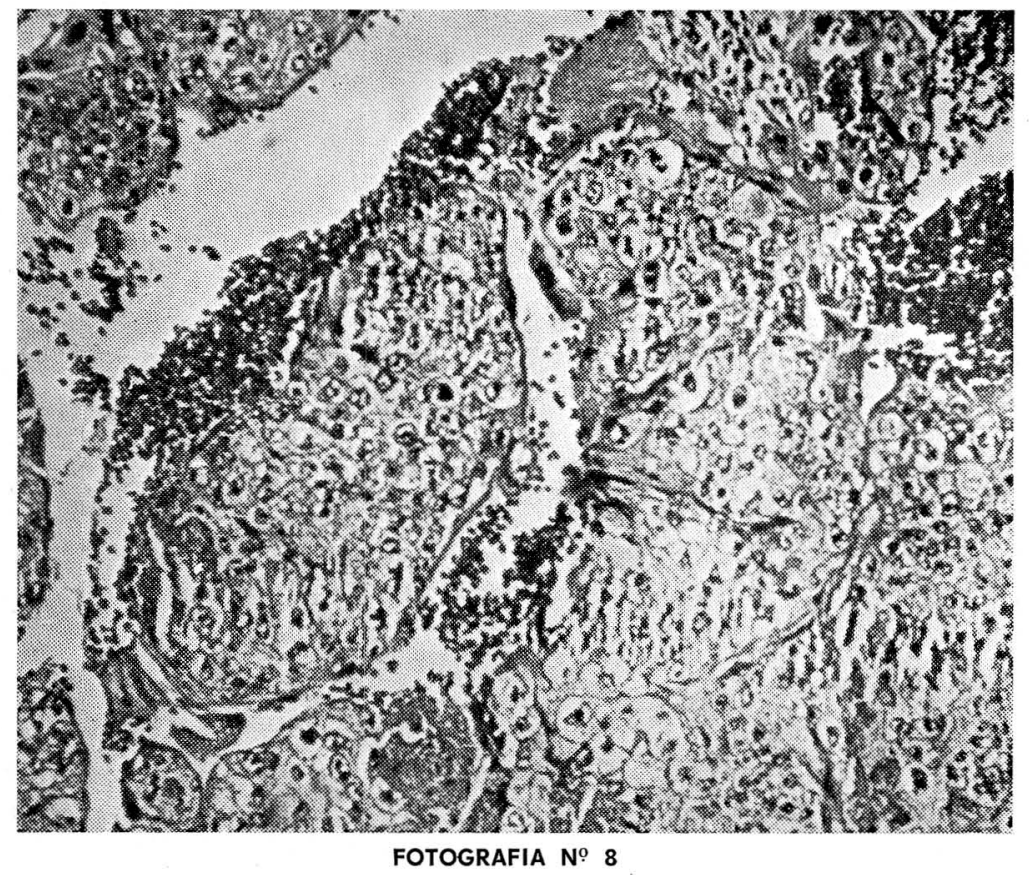

caso precedido de mola grado II preexistía tal patología.

\section{CORIOCARCINOMA}

\section{Definición}

Llamado también corioepitelioma por Marshand, se define como un tumor anaplástico epitelial puro constituído por células sincitio y citotrofoblásticas pero en el cual la estructura de la vellosidad está ausente. Obsérvese la microfotografía № 8.

Aún cuando los factores etiológicos son los mismos señalados para la mola, sin embargo el coriocarcinoma se ha encontrado más en primigrávidas y en multíparas viejas. También se ha visto aumentada su frecuencia en casos de incompatibilidad sanguínea del grupo $O$ a los grupos $A, B$ y $A B$.

Daamen y cols. (34) y Scott (91) lo consideran como una prueba de la carencia de anticuerpos maternos.

lliya y cols. (61) sugieren que la frecuencia elevada de coriocarcinoma en los países orientales resultaría de una falla en el mecanismo de formación de anticuerpos maternos entre matrimonios consanguíneos. De acuerdo con Tow (105) se puede hablar de un balance entre la resistencia del huésped y los estímulos carcinogenéticos en relación con el coriocarcinoma latente cuando la enfermedad se manifiesta muchos años después de un embarazo o de otra enfermedad trofoblástica.

Según Gallmeier y cols. (48) el coriocarcinoma descle el punto de vista morfológico constituye un carcinoma sincitial pero en cuanto a su génesis debe ser visto como un trasplante homólogo del hijo a la madre. 


\section{Relación huésped - tumor}

De acuerdo con la actualización de Li (69) los tumores trofoblásticos gestacionales son el producto de un conceptus con componentes genéticos tanto maternos como paternos. La relación huésped - tumor es en este caso similar a los trasplantes homólogos y está, teóricamente, sometido a rechazo inmunológico. Esta suposición se basa en la ocasional regresión espontánea de neoplasias trofoblásticas y de metástasis pulmonares de trofoblasto de embarazos normales. Mathé y cols. observaron aglutininas circulantes contra los leucocitos y trombocitos de los esposos en pacientes con coriocarcinoma. Además, Mogensen y Kissmeyer, Nielsen e Ivankova y cols., analizando la histocompatibilidad de antígenos en la HL-A locus en mujeres con Enfermedad Trofoblástica y sus esposos, mostraron que había con frecuencia un alto grado de histoincompatibilidad y que anticuerpos antileucocitos estaban presentes en el suero de mujeres con este tumor. Además, Lewis y cols. y Halbrecht y Komlos encontraron gran cantidad de linfocitos transformados en el cultivo de leucocitos de pacientes con Enfermedad Trofoblástica reaccionando contra los leucocitos de sus esposos.

Por otra parte Elston estudiando histológicamente los cortes de tumores trofoblásticos notó infiltración de linfocitos, histiocitos y células plasmáitcas en especímenes de 13 de 33 pacientes de las cuales 10 han sobrevivido sin evidencia actual de enfermedad al paso que solo 7 de 20 pacientes en las cuales se observó muy poca o ninguna infiltración sobrevivieron. Esto indica, al decir de $\mathrm{Li}$, que estas células sí expresan isoantigenicidad, demostrada por los linfocitos maternos. Currie ha identificado, además, una cubierta peritrofoblástica de sialomucina que ejerce un fuerte efecto electronegativo repeliendo los linfocitos cargados negativamente. Con esto él explica el estado de comprensión inmunológica existente in vivo entre el feto y la madre. Cuando ésta cubierta es quitada' in vitro, ocurre la interacción inmunológica entre el trofoblasto y los linfocitos maternos.

Estos conceptos han servido de soporte a las investigaciones de Doniach, Crookston y Cope, Cinader y cols. y Jakoubkova y cols., citados por $\mathrm{Li}$, quienes han inmunizado activamente con células espermáticas o leucocitos de los esposos a las pacientes de Enfermedad Trofoblástica, notando remisiones. Sus experiencias sin embargo no fueron definitivas porque estas enfermas habían recibido también quimioterapia.

\section{Incidencia}

La incidencia geográfica del coriocarcinoma varía tanto como la de la mola hidatiforme contrastando, al igual que en las otras formas de la Enfermedad Trofoblástica, la frecuencia elevada en los países de oriente con la poca ocurrencia en los occidentales. El siguiente cuadro muestra algunos datos estadísticos y permite comparar nuestros propios hallazgos con base en el estudio de 7 casos por nosotros controlados. 


\begin{tabular}{llllllll} 
Autor & País & \multicolumn{2}{l}{ Embarazos } & \multicolumn{2}{c}{ Partos } \\
Haseyawa (54) & Japón & 1 & $\times 300$ & & & \\
Wei y col. (111) & Taiwan & 1 & $\times$ & 496 & & & \\
Reddi (88) & India & 1 & $\times$ & & & & \\
Poen (87) & Indonesia & 1 & $\times$ & 1.115 & & & \\
Chan (30) & Malaya & 1 & $\times$ & 1.331 & & & \\
Presente estudic & & 1 & $\times$ & 10.214 & 1 & $\times$ & 7.824 \\
Schuman (95) & U. S. A. A. & 1 & $\times$ & 12.847 & & & \\
Villavicencio (112) & Chile & 1 & $\times$ & 24.000 & & & \\
Jouravieff (65) & Rusia & 1 & $\times$ & 26.000 & & & \\
Soberon (98) & México & 1 & $\times$ & 27.795 & & & \\
McGregor (72) & México & 1 & $\times$ & 44.000 & & & \\
Alter (6) & U. S. A. & 1 & $\times$ & 53.000 & & &
\end{tabular}

Nótese cómo dentro de un mismo país, México y EE. UU., por ejemplo, las variaciones estadísticas son sor- prendentes, fenómeno también observado en Colombia como se desprende del siguiente cuadro:

\section{Autor}

Valencia (107)

Acosta (1)

Vergara $(110)$

Duarte (39)

Presente estudic
Ciudad

Manizales

Barranquilla

Bogotá

Cúcuta

\section{Embarazos}

$\begin{array}{lll}1 & x & 2.832 \\ 1 & x & 4.363 \\ 1 & x & 5.084 \\ 1 & \times & 7.068 \\ 1 & x & 10.214\end{array}$

\section{Morfología}

A partir de sus estudios histopatológicos Hertig y Sheldon (60) y Hertig y Mansell (58) Ilamaron la atención sobre la semejanza entre las células trofoblásticas vistas en el coriocarcinoma y el patrón trofoblástico del huevo de 14 días. Novak (80) y Novak y Seah (81) insistieron en la forma de crecimiento del tejido coriocarcinomatoso y disienten del criterio de Hertig y cols. en cuanto a las características de mitosis e hipercromatosis como propios del coriocarcinoma, pues tales cambios pueden estar también presentes en molas benignas. Sin embargo están de acuerdo con el hecho de que la presencia de vellosidades está en contra del diagnóstico de coriocarcinoma. No obstante lo anterior, Brewer y Ger- bie (22) recientemente observaron 2 casos en los cuales un pequeño coriocarcinoma se encontró incluído en la placenta después del parto de niños normales y sugirieron la posibilidad de que el coriocarcinoma esté rodeado por vellosidades coriales en etapas tempranas de su desarrollo.

De acuerdo con la opinión de Novak, la invasión trofoblástica del coriocarcinoma se confirma con la presencia de columnas o racimos celulares que destruyen otras células causando necrosis y hemorragias.

\section{Hechos clínicos}

La correlación entre coriocarcinoma, edad de las pacientes y número de gestaciones y partos se establece para nuestro estudio como sigue: 


\section{CORIOCARCINOMA DISTRIBUCION SEGUN EDAD $Y$ NUMERO DE GESTACIONES}

\begin{tabular}{|c|c|c|}
\hline Caso & Edad & Gestación y Paridad \\
\hline 1 & 22 & G3 P2 $\mathrm{Ml}$ \\
\hline 2 & 24 & G4 P4 \\
\hline 3 & 25 & $\begin{array}{lll}\text { G2 } & \text { P1 } & A 1\end{array}$ \\
\hline 4 & 31 & G6 P5 M1 \\
\hline 5 & 35 & G7 P6 A1 \\
\hline 6 & 39 & G5 P4 M1 \\
\hline 7 & 50 & G9 P8 M1 \\
\hline
\end{tabular}

Los datos anteriores están en contra del concepto más ampliamente difundido en cuanto a que la frecuencia sea mayor en primigrávidas y multíparas viejas pues ninguna de las dos circunstancias fue confirmada. Cuatro casos estuvieron precedidos de mola hidatiforme, dos de aborto y uno de embarazo normal.

De acuerdo con el "Albert-Mathiew Memorial Chorioepithelioma Registry", el $46 \%$ de los coriocarcinomas gestacionales está precedido de mola hidatiforme' $41 \%$ por embarazos normales o abortos y 12 a $14 \%$ de corioadenoma destruens.

El intervalo entre el diagnóstico del coriocarcinoma y el embarazo que lo antecedió fue variable entre uno y cuatro meses correspondiendo los casos extremos a embarazo molar.

El diagnóstico clínico y patológico se llevó a cabo en circunstancias diversas por lo cual consideramos importante reseñarlas:

CASO No 1 - Historia 198762 - G3 P2 M1, 22 años, mola grado II. Un mes después de evacuada la mola, y en presencia de subinvolución uterina y flujo sanguinolento se repitió el raspado hallándose coriocarcinoma al estudio. A.P. Las reacciones biológicas eran negativas.

CASO No 2 - Historia 184082 - G4 P4, 24 años. Dos meses después de parto normal hemorragia genital con tumor endouterino. Reacciones biológicas positivas $(20.000$ U.) e imá- genes radiográficas pulmonares de metástasis. Biopsia del tumor positiva para coriocarcinoma.

CASO No 3 - Historia 209692 - G2 P1 A1, 25 años. Un mes después de un raspado por aborto (?) laparotomía por cuadro abdominal agudo y shock. Utero perforado por tumor proyectado a la cavidad abdominal. A.P. coriocarcinoma.

CASO No 4 - Historia 221455 - G6 P5 MI, 31 años. Un mes después de raspado por mola 11 , en presencia de flujo sanguinolento, y reacciones positivas se practicó raspado biopsia. A.P.: coriocarcinoma.

CASO No 5 - Historia 207156 - G7 P6 Al, 35 años. Después de 4 meses de hemorragia se practicaron 2 raspados con diagnóstico de aborto (?) El estudio A.P. del $2^{\circ}$ raspado informó coriocarcinoma. Reacciones biológicas positivas ( 40.000 U.).

CASO No 6 - Historia 58381 - G5 P4 MI, 39 años. Cuatro meses después de evacuada mola grado II, reacciones biológicas positivas. Raspado biopsia que mostró signo de Arias SteIla. Prolapso genital de II grado. Histerectomía. A.P.: coriocarcinoma intramural.

CASO No 7 - Historia 214474 - G9 P8 M1, 50 años. Después de 2 meses de aborto molar, subinvolución uterina y hemorragia genital. Raspado biopsia. A.P.: coriocarcinoma. Reacciones biológicas negativas.

Del análisis de los fenómenos registrados se concluye que el antecedente de mola hidatiforme, la presencia de útero aumentado de tamaño, la hemorragia genital o el flujo serosanguinolento y las reacciones biológicas fueron los datos más importantes para el diagnóstico clínico. Además se le concedió gran valor al signo de Arias Stella como reflejo de la acción gonadotrópica de la neoplasia corial sobre el tejido endometrial. Solamente en el Caso № 1, la neoplasia se acompañó de quiste ovárico unilateral.

\section{Metástasis}

Tres pacientes, las correspondientes a los casos 2, 3 y 7 , hicieron metástasis pulmonares diagnosticadas radiográficamente y en una de 
ellas interpretadas inicialmente como lesiones tuberculosas. Al respecto vale la pena mencionar que esta confusión diagnóstica no es extraña teniendo en cuenta las características que en ocasiones adoptan. Magrath y cols. (71) en su revisión sobre las lesiones metastásicas del coriocarcinoma refieren el caso de una paciente a quien, sometida a tratamiento con ácido para-aminosalicílico e isoniazida dadas las lesiones pulmonares reveladas por los rayos $X$ y fallecida algún tiempo después, mostró a la necropsia metástasis parenquimatosas de coriocarcinoma en ambos pulmones. Por las experiencias citadas anteriormente valdría la pena reconsiderar la pretendida asociación tuberculosis - enfermedad trofoblástica invocada por varios autores e inclusive mencionada dentro de la génesis de la neoplasia. También ocurrieron metástasis en el cerebro de la paciente citada con el número 2 y en vagina en el caso $N$ ․ 3. De acuerdo con Novak (82) la manera de propagarse las metástasis del epitelio corial recuerda más el sarcoma que el carcinoma. Aún en la pelvis la invasión es vascular aún cuando también los linfáticos puede nestar incluídos.

\section{Tratamiento}

Siguiendo los lineamientos generales de las tendencias actuales acerca de la metodología terapéutica y manejo del coriocarcinoma, las pacientes de nuestro estudio fueron sometidas a la siguiente terapia:

Caso No 1 - G3 P2 M1, 22 años. Quimioterapia (MTX).

Caso No 2 - G4 P4, 24 años. Quimioterapia inicial, luego histerectomía con anexectomía y más tarde nuevas series de quimioterapia (MTX y 6-mercaptopurina).
Caso № 3 - G2 P1 A1, 25 años. Histerectomía y luego quimioterapia (MTX Actinomycin D). Resección de metástasis vaginales.

Caso N: 4 - G6 P5 M1, 31 años. Quimioterapia (MTX - Actinomycin D).

Caso № 5 - G7 P6 A1, 35 años. Histerectomía anexectomía y luego quimioterapia (MTX).

Caso № 6 - G5 P4 M1, 39 años. Histerectomía vaginal, biopsia de ovarios y luego Quimioterapia (MTX-Actinomycin D).

Caso N: 7 - G9 P8 M1, 50 años. Histerectomía - anexectomía y luego Quimioterapia (MTX - Actinomycin D).

Con base en lo propuesto en el protocolo de nuestra investigación clínica se pretendió hacer quimioterapia exclusivamente en pacientes jóvenes, casos 1 y 4 , y reservar la cirugía, combinada con los citostáticos, para pacientes de edad o para las complicaciones ( $\operatorname{casos} 2,3,5,6$ y 7 ).

\section{Quimioterapia}

Como fármacos se utilizaron el amethopterin (Methotrexate) la 6mercaptopurina (Purinetol) y el Actinomycin D (Cosmegen), a las siguientes dosis promedio:

MTX: $20 \mathrm{mlgr}$. por día, por vía oral y por serie de 5 días.

Purinetol: 2 mlgr. por kilo y por día; vía oral.

Cosmegen: 0,5 mlgr. por día, vía endovenosa, 5 días.

Antes, durante y después de la prescripción de los quimioterápicos se tuvieron en cuenta las precauciones y requisitos: cuadro hemático, recuento de plaquetas, pruebas de 
función hepática (Hanger - Timol Transaminasas) y renales (creatinina-azoemia).

La quimioterapia se utilizó en todos los casos tratados, en 2 de ellos como terapia fundamental y exclusiva y en los restantes combinada con la cirugía. Fue empleado un solo medicamento (MTX) o dos, de manera conjunta o secuencial: MTX y Purinetol o MTX y Actinomycin D.

Sin excepción todas las pacientes hicieron manifestaciones tóxicas de grado variable, estomatitis y vaginitis principalmente. Anorexia, vómito y diarrea fueron frecuentes. Alopecia ocurrió en 2 casos. También se observaron leucopenia y trombocitope- nia presentándose en breve tiempo franca inversión de la fórmula con linfocitosis marcada la cual persiste en varias enfermas aún después de más de un año de tratadas. No fue, sin embargo, necesario suspender en ningún caso la terapia y por el contrario en 3 de ellas hubo de repetirse.

\section{Evolución y Resultados}

Con base en los controles clínicos' biológicos y radiológicos y queriendo buscar alguna correlación entre los distintos casos clínicos, su tratamiento y los resultados, presentamos el estado actual de nuestra investigación:

\section{Caso}

1
2
3
4
5
6
7

A pesar de que el tiempo de control de los casos estudiados aún no es suficiente para emitir un juicio definitivo debemos convenir que, en tratándose de neoplasias de alta malignidad, cuya evolución, sin la terapia adecuada, suele ser fatal en menos de un año, consideramos que los resultados son altamente satisfactorios. Es importante advertir que hemos utilizado para el control biológico la cuantificación ganadotropa por medio del peso del útero de la ratona siguiendo la técnica de Albert, siendo en la actualidad las reacciones negativas.

Debemos analizar aspectos santes de la historia clínica
T. de Control

23 meses
8 "
13 "
18 "
17
15 "'
13 "

\section{Conds. actuales}

Buenas

Muerta

Buenas

Buenas

Buenas

Buenas

Buenas

pondiente al caso № 2 del presente estudio:

G4 P4, 24 años. Coriocarcinoma a partir de una gestación y parto aparentemente normales. Fue sometida a tratamiento citostático con regresión parcial de las metástasis pulmonares y una vez extirpado el tumor endouterino. Las reacciones biológicas se negativizaron. Después de 2 series de MTX hubo de ser histerectomizada en vista de la reaparición de las hemorragias y la positividad nuevamente presente de las reacciones biológicas. La anatomía patológica reveló focos de coriocarcinoma intramiometriales.

Sucesivas series de MTX solo o asociado a Purinetol no fueron sufi- 
cientes para impedir la aparición de metástasis cerebrales que al final condujeron a la muerte de la paciente.

Es de nuestra investigación el único caso de mortalidad y a propósito de él vale la pena hacer las siguientes consideraciones:

1. Es extraño ver como el único caso desafortunado ocurrió en una paciente con antecedente de parto y no de mola o de aborto.

2. Pese a la intensa terapia citostática sus efectos sobre los elementos figurados de la sangre fueron mínimos pues salvo al comienzo del tratamiento, cuando se observó ligera disminución de los leucocitos, éstos progresivamente alcanzaron su número normal. La linfocitosis, a diferencia de lo observado en el resto de los casos de Enfermedad Trofoblástica, tratados con quimioterapia, fue muy discreta y las plaquetas permanecieron invariablemente normales.

3: Los efectos de la quimioterapia observados tanto a nivel de la neoplasia primaria o de sus metástasis como sobre el leucograma nos permiten formular varias hipótesis: a) la posibilidad de encontrarnos frente a un caso de resistencia a la acción de los citostáticos por parte del tumor y/o de la paciente, deducible por el progresivo crecimiento de la neoplasia y el efecto despreciable de las drogas sobre leucocitos y trombocitos; b) Efecto inmunosopresor de la medicación citostática que trastornó los mecanismos inmunológicos maternos? c) Había congruencia antigénica entre el huésped y el tumor $y$ en tal virtud la neoplasia se desarrolló sin influencia inmunológica materna?
A propósito de las posibilidades mencionadas merecen citarse los trabajos de Gallmeier y cols. (48) de acuerdo con los cuales las relaciones inmunológicas entre un tumor y el organismo anfitrión dependen de la envergadura de sus diferencias antigénicas con 3 posibilidades:

1. Existe congruencia (igualdad) antigénica entre el tumor y el huésped.

2. El tejido tumoral presenta un mosaico antigénico incompleto del anfitrión (pérdida de antígenos) y

3a El tejido tumoral presenta mayor número de antígenos que el tejido que le diera origen. Tales antígenos pueden ser específicos del tumor, del órgano o de la especie (por Ej.: Antígenos de histocompatibilidad).

En los dos primeros casos el tumor se desarrolla sin intervención del sistema inmunitario del anfitrión. En la tercera posibilidad el mecanismo inmunológico del huésped se inclina hacia la inmunotolerancia o hacia la formación de anticuerpos.

Las consideraciones anteriores permitieron sugerir a los autores mencionados el establecimiento de una terapia citostática electiva y acorde con las reacciones inmunes y el grado de similitud o desimilitud antigénica.

\section{ANTICONCEPTIVOS $Y$ ENFERMEDAD TROFOBLASTICA}

Habiendo observado una incidencia inusitadamente alta, 18 casos de mola hidatiforme y 3 de coriocarcinoma, para $18,7 \%$ del total de pacientes con Enfermedad. Trofoblástica, que habían recibido anticonceptivos orales, quisimos investigar la posible relación de causa a efecto. 
MANEJO DE IA ENFERMEDAD TROFOBIASTICA

Ios esquomas siguientes resumen la metodolosia seguida en nuestra investigación clínica:

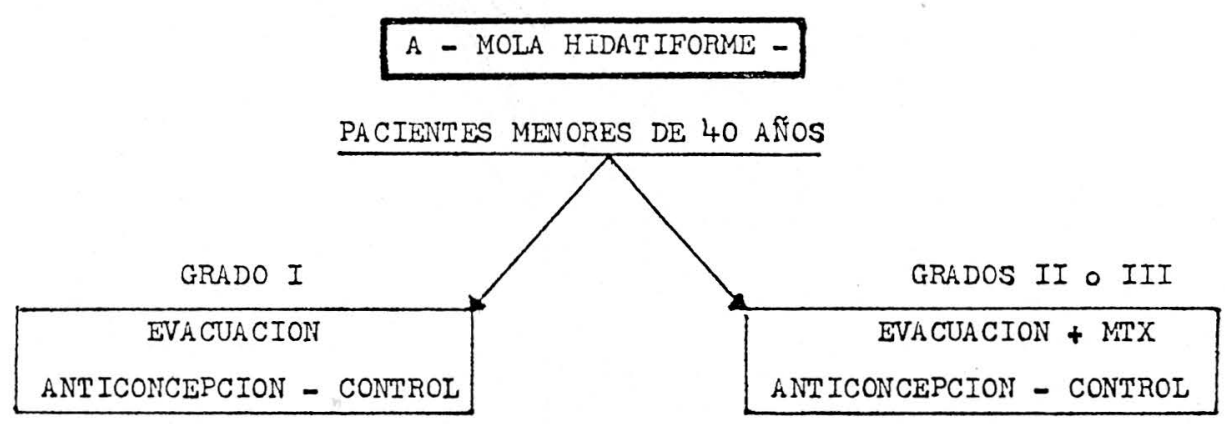

\section{PACIENTES DE 40 AT̃OS O MAS}

I- HISTERECTOMIA - OOFORECTOMIA SELECTIVA - Y MTX DE ACUERDO CON INFORNE DE ANATOMIA PATOLOGICA

0

2- EVACUACION Y DECISION POSTERIOR SEGUN INFORME DE ANATOMIA PATOLCGICA

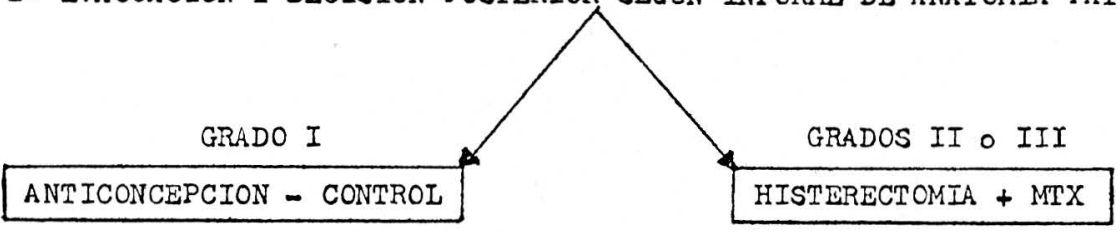




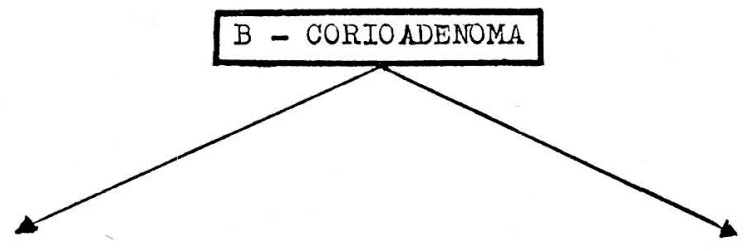

PACIENTES IITNORES DE 40 ANTOS PACIENTES DE 40 AÑOS O MAS

MTX - ANTICONCEPCION - CONTROIES

HISTERECTOMIA + MTX

C - CORIOCARCINOMA

I - HISTERECTONIA - OOFORECTOMIA SELECTIVA - QUINIOTERAPIA: MTX + ACTINONYCIN

2 - EN CASOS DE TXCEPCION : QUMIOTERAPIA : MTX + ACTINOMYCIN

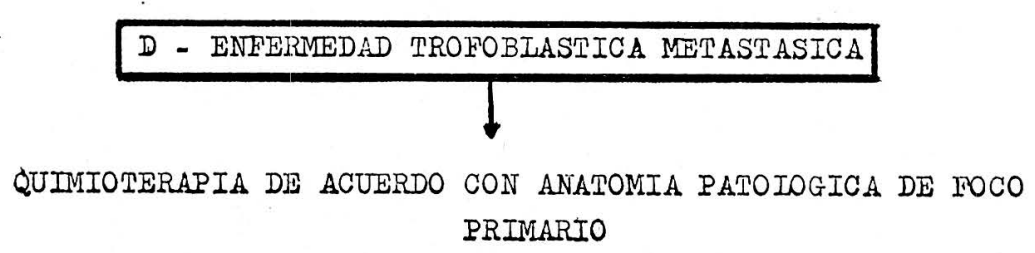

A partir del hallazgo de Carr (26) en 1963, de triploidia (69, XYY) en el análisis cromosómico de un aborto de una pequeña mola, se han estudiado los aspectos citogenéticos de la degeneración trofoblástica.

Makino y cols. (74) encontraron triploidia $(69, X X Y)$ en el cultivo de 3 especímenes que mostraban degeneración hidrópica. También Schle- gel y cols. (94) y Boué y cols. (19) describieron asociación etnre vellosidades coriónicas quísticas y triploidia.

De otro lado Carr (27) encontró aberraciones cromosómicas en 6 de 8 especímenes con degeneración hidrópica, de pacientes que recientemente habían suspendido la ingestión de contraceptivos y habiendo queda- 
do embarazadas abortaron, cifra que fue considerada estadísticamente muy significativa puesto que solo en $23 \mathrm{ca}-$ sos de 521 abortos de series no seleccionadas hubo también anomalías citogenéticas.

Queriendo encontrar explicación a tal fenómeno el autor sugirió la hipótesis del aumento de la hormona luteinizante como causa de la poliploidia, pues se sabe que en ciertos primates esta hormona produce cam. bios en la zona pelúcida y tal circunstancia podría interferir con la expulsión del segundo cuerpo polar y afectar precozmente el zigote.

Existe también la hipótesis según la cual la acción anticonceptiva de los progestativos se ejercería a nivel de los cromosomas y los trabajos de William y cols. (113) del Colegio de Medicina de la Universidad de Tennessee tienden a demostrarlo al provocar transformaciones morfológicas de los cromosomas e inhibición de la meiosis en el perro por medio de la progesterona. Hallazgos semejantes lograron Beaconsfield y Ginsburg (15) de la Escuela de Medicina del Royal Free Hospital Inglés, administrando de manera prolongada progesterona: inhibición de la meiosis, diploidia anormal y aglomeración de núcleos fueron vistas en el ovocito de la rata.

Recientemente Wagner y Richart (106) mostraron la relación existente entre la excesiva estimulación hormonal, el signo de Arias Stella y poliploidia del endometrio.

Además Erving y Bower (43) reportaron el caso de mola hidatiforme en una paciente que recibía clomiphene, reafirmando así la opinión de desequilibrio endocrino como precipitante del síndrome.

Según Carr, es posible que el des- equilibrio hormonal pueda afectar precozmente el desarrollo de las vellosidades y en tal sentido el compromiso hepático en pacientes de bajas condiciones socio-económicas y por consiguiente desnutridas explicaría la elevación de los niveles sanguíneos de estrógenos y la producción subsecuente de LH.

Frente a nuestros hallazgos y experiencias, es la ocasión de preguntarnos si la presencia de 3 coriocarcinomas y 18 molas en pacientes que recientemente habían suspendido la ingestión de los llamados anovulatorios, no es una evidencia clínica más a favor de las hipótesis de Carr. Si ello fuera así, tendríamos que admitir la posibilidad de ver aumentada la incidencia de la Enfermedad Trofoblástica en la medida y cantidad en que se empleen los contraceptivos hormonales.

\section{Resumen y Conclusiones}

La Enfermedad Trofoblástica ofrece un campo apasionante a la investigación oncológica. En efecto, su frecuencia variada, geográfica y racial, su discutible fisiopatogenia y la controversia acerca de su clasificación, son problemas por definir. Pero más importantes aún son los aspectos citogenéticos e inmunológicos que en la actualidad se discuten.

Nuestro estudio ha sido eminentemente clínico-patológico y a ese respecto podemos aportar datos de interés y que consignamos a manera de conclusiones. La frecuencia de la Enfermedad Trofoblástica en Colombia es, de acuerdo con lo encontrado por diversos autores nacionales, importante. Quizá en ella tengan ingerencia factores étnicos, de nutrición y de salud en general, que convendría investigar como que son factores predisponentes del síndrome. Se pone de manifiesto la necesidad de uniformar 
criterios de diagnóstico a fin de establecer con precisión la frecuencia general de la enfermedad en nuestro país y sus distintas modalidades.

Acorde con lo anterior debe establecerse la metodología del estudio histológico incluyendo la toma de material. Nuestra casuística reveló que, aparentemente, la severidad de los cuadros histológicos fue ajena al número de gestaciones pero no a la edad de las pacientes con la cual guardó relación directa.

Se impone un estudio más a fondo sobre las condiciones paternas: edad, salud y ocupación, factores que pueden influir en la génesis de la enfermedad.

El signo clínico más constante fue la hemorragia que unida a la ausencia de dolor debe ser considerada para el diagnóstico oportuno.

La toxemia gravídica fue frecuente y su ocurrencia aumentó a medida de la severidad histopatológica de la neoplasia y no siempre en relación con el tamaño uterino. Por lo tanto debe admitirse que, aparentemente, es la actividad histofuncional del trofoblasto y no su crecimiento el único determinante de la disgravidia hipertensiva. El crecimiento anormal del útero debe ser tenido en mente para el diagnóstico pero no solo en cuanto a exceso sino aún por defecto. Casos hubo, además, de proporcionalidad entre la amenorrea y el tamaño uterino.

Hacemos énfasis acerca de las manifestaciones cardiovasculares de la enfermedad no solamente en cuanto a hipertensión arterial sino, principalmente, al eretismo cardíaco y la taquiesfigmia encontrados por nosotros más frecuentemente en pacientes con formas avanzadas de la enfermedad y presumiblemente en rela- ción con la interacción hormonal trofoblástico-tiroidea.

La presencia de patología ovárica, estadísticamente importante en nuestro estudio, no tuvo mayor relación con las formas histológicas de la enfermedad. El hecho de que no hubiera ocurrido ninguna complicación: torsión, infección o ruptura, nos inclina a reafirmar que la conducta expectante debe ser la norma pues cabe esperar su regresión espontánea.

La histerografía es un procedimiento valioso y su práctica sencilla $e$ inocua; debs intensificarse como recurso diagnóstico de los tumores trofoblásticos.

La cuantificación hormonal de godanotropinas debe tener valor entendido en el diagnóstico de la Enfermedad Trofoblástica pues cifras altas pueden encontrarse en embarazos normales y eliminaciones bajas pueden hallarse en las formas más graves como el corioadenoma y el coriocarcinoma.

Nuestra experiencia demostró que el cuadro histopatológico de los distintos grados de la enfermedad mantuvo relación con la evolución ulterior. Por consiguiente es nuestra impresión que la clasificación histológica de Hertig y Mansell debe conservarse. Es necesario intensificar los estudios a fin de confirmar el potencial de malignidad de las distintas formas histológicas y primordialmente del corioadenoma.

De acuerdo con lo anterior creemos que se puede establecer una diferente metodología terapéutica acorde con los estudios histológicos $v$ además convenir que el manejo de la Enfermedad Trofoblástica debe tener lineamientos generales con variantes que dependan de las condiciones individuales de las pacientes principal- 
mente con la edad y el número de gestaciones.

Somos de opinión que mientras en la mola hidatiforme grado I la inteligente observación post-evacuación puede ser la regla, en los grados II - más, la quimioterapia debe ser empleada a fin de evitar la degeneración maligna y las complicaciones.

El manejo del coriocarcinoma en la actualidad tiene en los quimioterápicos su arma más valiosa pero no descarta las posibilidades quirúrgicas principalmente cuando surgen las complicaciones o cuando la neoplasia afecta a pacientes de vida generativa consumada.

Si bien es cierta y conocida la bondad de las drogas citostáticas, su empleo exige requisitos y controles meticulosos cuya omisión puede resultar peligrosa y aún mortal.

Se pone en duda la correlación entre tuberculosis pulmonar y Enfermedad Trofoblástica como situación nosológica conjunta y a cambio se da énfasis a los estudios radiográficos de las metástasis de la neoplasia corial, presumiblemente confundidas con las lesiones bacilares.

Presentamos un esquema de terapia y manejo de la Enfermedad Trofoblástica que ha orientado nuestro estudio y cuyos resultados han sido analizados a lo largo de esta exposición. De ellos se destaca que solamente hubo un caso fatal en 112 tratados.

Reafirmamos la necesidad del control prolongado de las pacientes que han sido tratadas e insistimos sobre la conveniencia de recomendar la anticoncepción, no hormonal, ante la posibilidad de que un nuevo embarazo dificulte la interpretación de las pruebas biológicas indispensables pa- ra el seguimiento de la enfermedad. Además, creemos que en pacientes que recientemente han recibido medicamentos antifólicos y citostáticos pueda haber trastornos en el desarrollo embrionario y efectos teratógenos en una gestación demasiado próxima.

Aún cuando los nuevos procedimientos de inmunovaloración isotópica son los que brindan mayor seguridad en el diagnóstico y control de la evolución de la enfermedad, los exámenes clínicos, biológicos y radiológicos siguen teniendo plena vigencia y valor.

Planteamos la posibilidad de que haya diferencias entre la biología del coriocarcinoma desarrollado a expensas de un embarazo considerado como normal y el originado en otro tipo de gestación.

Con base en nuestros nropios hallazgos y el respaldo de investigaciones foráneas sugerimos la necesidad de profundizar en el estudio de la acción de las hormonas administradas como anticonceptivos sobre los. cromosomas y su posible relación con la Enfermedad Trofoblástica.

\section{Sumario}

Se presenta el estudio de 112 casos de Enfermedad Trofoblástica, realizado en el Servicio de Toxemias del Instituto Materno Infantil de Bogotá, de los cuales 97 correspondieron a Mola Hidatiforme, 8 a Corioadenoma y 7 a Coriocarcinoma. Teniendo en cuenta los porcentajes encontrados se deduce que su frecuencia hospitalaria tiene importancia en el medio investigado.

Se actualizó el tema insistiendo en los mecanismos inmunológicos y genéticos comprometidos en la fisiopatogenia del síndrome. 
Los autores recomiendan los procedimientos clínicos y paraclínicos más útiles para el diagnóstico.

Con base en la clasificación histopatológica de Hertig y Mansell y los fármacos disponibles en la actualidad, se elaboró un esquema terapéutico cuya metodología fue seguida estrictamente en el manejo de las pacientes. Se exponen los resultados obtenidos.

Se insinúan algunas hipótesis etiopatogénicas en relación con la enfermedad y la conveniencia de profundizar en la investigación de las mismas.

\section{Summary}

A study on 112 cases of trophoblastic illness is hereby presented accomplished a the Toxemia Service of the Instituto Materno Infantil of Bogotá, of which 97 corresponded to Mola Hydatidiform, 8 to choriocadenoma and 7 to choriocarcinoma. Keeping in mind the above percentages, is may be deducted that their hospitalization frequency has importance for the investigated field.

The subject was up-dated by insisting in the immuniological and genetical mechanisms engaged in the physiopathogenesis of the syndrome.

The authors recommended clinical and para-clinical procedures as the most useful for diagnosis.

On the basis of the hystopathological classification of Hertig and Mansell and the pharmacon available at present, a therapeutical plan, which method was strictly followed in handling the patients, was prepared. The results obtained are included herein.

Certain hypothesis are suggested with reference to the illnes and the convenience of further investigation of same.

\section{BIBLICGRAFIA}

1 ACOSTA-BENDEK, E.: Rev. Col. de Obs. y Gin. 15: 233; 1964.

2 ACOSTA-SISON, H.: Obstet. and Gynec. 20 : $103 ; 1962$.

3 ACOSTA-SISON, H.: Obstet. and Gynec. 9: $233 ; 1957$.

4 ACOSTA-SISON, H.: Amer. J. Obst. Gynec. $71: 1279 ; 1956$

5 ACOSTA.SISON, H.: Amer. J. Obstet. Gynec. 81: $715 ; 1961$.

6 ALTER, M. \& COSGROVE, A.: Obstet. and Gynec. 5: 755; 1955.

7 ALVAREZ, H.: Gin. et Obst. 69: 581; 1970.

8 ALVAREZ, H.: Amer. J. Obstet. Gynec. 95: $538 ; 1966$.

9 ARAMBURU, G.: Mem. III Cong. Lat. Am. Ginac. Obst. 2: 576; 1958.

10 BABUNA, C.: Obst. and Gynec. 35: 852; 1970.

11 BAJA-PANLILIO, H.: Intrenational Surgery. 54: $210 ; 1970$

12 BAJA-PANLILIO, H.: \& APELO, R.: Philip. Surg. 20: 171; 1965.

13 BAYAN, F.: APELO, R.: Philipp. J. Surg. C'bst. \& Gynec. 2: 1; 1957.

14 BAYER, R.: Art. Gynak. 172: 198; 1941.

15 BEACONSFIELD y GINSBURG. Citados por J. G. C. C.: Progresos de Terapéutica Clínica. Vol. XXII, Fascículo 3: 714; 1969.

16 BOBROW, M. \& FRIEDMAN, S.: Amer. J. Obstet. Gynoc. 73: 448; 1957.

17 BEISCHER, N. \& FORTUNE, D.: Amer. J. Obstet. Gynec. 100: 276; 1968.

18 BOOG, G., MULLER, D., MAYER, E., DEMOT et GANDAR, R.: Bulletin, Gyn. et Obs. 22 : $253 ; 1970$.

19 BOUE, J. BOUE, A. and LAZAR, P.: Ann. Genet (Paris) 10: 179; 1967.

20 BOURGOIN, P., BAYLET, T. R., BALLON, C \& GRATTEPANCHE, H.: Rev. Franc. Gynec. 60: 673; 1965. 
21 BUR, G., HERTING, A., MCKAY, D. \& ADAMS, E.: Obstet. and Gynec. 19: 156; 1962.

22 BREWER, J., \& GERBIE, AB.: Choriocarcinoma, Vol. 3 of UICC Monograph Series, edited by Holland J. F., Hreshchyshyn M. M. Berlin. Springer Verlag, p. 45; 1967.

23 BRINDEAU, A.: Bull. Fed. Soc. Gynec. et Cbstet. 4: 3; 1952

24 CABRERA, H.: Bol. Soc. Chilena Obst. Clin. 11 : $107 ; 1946$.

25 CARCASSONE, Y., RUF. H.; et BLANC. B. Bull. de Gynec. et D'Obst. 3: 275; 1969.

26 CARR, D. H.: Obstetrics and Gynec. 3 : $333 ; 1969$.

27 CARR, D. H.: Lancet 2: 830; 1967.

28 COHEN, M., HAOUR, J., BERTRAND, J. et DUMONT, M.: Gynec. et Obst. 69: 197; 1970.

29 CROWELL, J.: North Caroline. M. J. 16 : $11 ; 1955$

30 CHAN D.: Brit. Me. J. 2: 953; 1962.

31 CHALMERS, J. A.: J. Obstet. Gynec. Brit. Emp. 55: 322; 1948

32 CHESLEY, L. COSGROVE, S. \& PREECE, I. Amer. J. Obstet. Gynec. 52: 311; 1946.

33 CHUN, D.: J. Obst. Gynaec. Brit. Comm. $71: 180 ; 1964$. 1964.

34 DAAMEN, C., BLOEN, G., \& WESTERBECK, A.: J. Obstet. Gynaec. Brit. Emp. 68: 144; 1961.

35 DEREK, LI.: J. Obst. Gynaec. Brit. Comm. 72: $242 ; 1965$.

36 DE SNOO, K. citado por Duarte, A. y cols. Rev. Col. Obs. y Gin. XXI: 387; 1970.

37 DIECKMANN, W.: The Toxemias of Pregnancy, St. Louis, 1952. The C. V. Mosby Company. p. 497.

38 DOUGLAS, G. W.: Surg. Clin. N. Amer. 37 : $379 ; 1957$.

39 DUARTE, A., ROLON, R., PALAU, M.: Rev. Col. de Obs. y Gin. 6: 585; 1970.

40 DUMITRESCU, P. \& DUMITRESCU, A.: Obst. Ginec. 2: 145; 1959. Sit. ni Excerpta Medica, Cbstet. Gynec. 13: 557; 1960.

41 EDMONDS H. W.: Ann. N. Y. Acad. Sci.
$80: 86 ; 1959$

42 EICHWALD, E. \& SILMSER, C.: Transplantion. Bull. 2: 148; 1955.

43 ERVING, H. W., \& BOWER, J.: Int. Surg. 47: 493; 1967.

44 FAVREAU, E., \& BELANGER, P.: Bull. Soc. Obstet. Gynec. 28: 179; 1939.

45 FERNANDEZ-DOBLADO, R.: Mem. III Congr. Mex. y Lat. de Gin. y Obs. 1958.

46 FERNANDEZ M. y MARQUEZ, C.: Rev. Gynec. e Obst. 100: 15; 1957.

47 FOX, F., \& TOW Amer. J. Obstet. Gynec. 95: $239 ; 1966$

48 GALLMEIER, W., BERTRANS, J., KUWERT, E., y SCHMIDT, C.: Medicina Alemana. 3: $1563 ; 1970$.

49 GREENE, R.: Ann. N. Y. Acad. Sci. 80: , 143; 1959

50 GOLDSTEIN, D.: Cls. Obs. y Gin. Dic. 945; 1970.

51 GORE, H., y HERTING, A.: Cls. Obs. y Gins. Junio: 276 ; 1967.

52 GOTTESFELD, K., TAYLOR, E., THOMSON, H., \& HOLMES, J.: Obstet. Gynec. 30: $163 ; 1967$.

53 HARPER, W. \& MAC VICAR, J.: Brit. Med. J. ii : $1178 ; 1963$.

54 HASEYAWA, T., KAWAI, N., NOZUE, G., SHINTANI, S., \& TAKAHARA, J.: J. Jap. Obstet. Gynec. Soc. 12: 186; 1965.

55 HAUSCHKA, T.: Transplantation. Bull. 2: $154 ; 1955$.

56 HERSHMAN, J. \& HIGGINS, H.: New England Journal of Medicine. 284: 573; 1971 .

57 HERSHMAN, J. \& STARNERS, W.: Journal of Clinical Investigation. 48: 923; 1969.

58 HERTIG A. \& MANSELL, H.: Atlas of Tumor Pathology. Armed Forces Institute of Pathology, Washington, D. C.; 1956.

59 HERTIG, A., \& EDMONDS, H.: Arch. Path. 30: $260 ; 1940$

60 HERTIG, A. \& SHELDON, W.: Amer. J. Obstet. Gynec. $53 ; 1 ; 1947$.

61 ILIYA, F., WILLIAMSON, S., \& AZAR, H. Cancer. 20: 149; 1967. 
62 IFFY, L.: Ann. Chri. Gynaec. Fenn. 51: 428; 1962.

63 IVANOV, J.: AKUSH. I Ginek. 5: 419; 1966.

64 JAKUBOV, I. \& CVETKOV, T.: AKUSH. i. Ginek. 5: 440; 1966.

65 JOURAVIEFF. Citado por Duarte, A., Rolón R., y Palau, M.: Rev. Col. de Obs. y Gin. 6: $587 ; 1970$

66 KIKA, K., MATUDA, I.: Report. Obstet. and Gynec. 9: 224； 1957.

67 KING, G.: Proc. Soc. Med. 49: 381 ; 1956.

68 LAUSLAHTI, K.: Acta Pathol. et Microbiol. Scand. Suplementum: 201; 1969.

69 LI, M. C.: Annals of Internal Medicine. 74: $102 ; 1971$.

70 LLEWELYN-JONES, D.: J. Obstet. Gynec. Brit. Cwlth. 72: 242; 1965.

71 MAGRATH, J., GOLDING, P. \& BAGSHAWE, K.: British Medical Journal. June: 633; 1971.

72 MCGREGOR, C. ONTIVEROS, E., VARGAS, E., CASTELAZO, L.: Gin. y Obs. de MéxiCO; XXI 611; 1966.

73 MCGREGOR, C.. ONTIVEROS, C., VARGAS, L., \& VALENZUELA, L.: Obstet. \& Gynec. 33: $343 ; 1969$.

74 MAKINO, S., SADAKI, M. S., \& FUKUSCHIMA, T.: Lancet, II, 1275; 1964.

75 MARQUEZ-MONTER, H., ALFARO, G., ROBLES, M. \& BOLIO, A.: Amer. J. Obstet. Gynec. 85: 856; 1963.

76 MATHE, G. DAUSSET J. HERVET E. COLOMBINI \& BRULE: Gynec. et Obstet. 64: 51; 1965.

77 MEYER, J.: Obstet. Gynec. 28: 826; 1966.

78 MORRISON, D.: J. Obstet. Gynaec. Brit. Cwith. 71: 640; 1964.

79 NOVAK, E. R. \& WOODRUFF, J. D.: Novak's Gynecologic and Obstetric Pathology. Fith. Edition. W. B. Saunders, Philadelphia. 1962. pág. 563-591.

80 NOVAK, E.: Am. J. Obst. \& Gynec. 59: $1355 ; 1950$.

81 NOVAK, E. \& SEAH, C.: Amer. J. Obstet. Gynec. 68: 376; 1954.
82 NOVAK, E. R., \& WOODRUFF, B.: Gyneco logic and Obstetric Pathology. W. B. Saunders Company. Philadelphia. London. 1966.

83 CBER, W.: Ann. N. Y. Acad. Sci. 80: 3; 1959.

84 PAGE, E.: Am. J. Obst. \& Gynec. 37: 291 1939.

85 PARK, W.: Ann. N. Y. Acad. Sci. 80: 152 1959.

86 PARK, W.: Choriocarcinoma, Vol. 3 of UICC Monograph Series, edited by Holland J. F., Hreshchyshyn. M. M. Berlin, Springer-Verlag, pág. 5; 1967.

87 POEN, H., \& DJOJOPRANOTO, M.: Amer. J. Obstet. Gynec. 92: 510; 1965.

88 REDDY, D.: J. Indian Med. Ass. 43: 287 1964.

89 RIVIERE, M., CHAUSTRUSSE, L. \& PAILLER J. L.: Gynec. et Obst. 65: 283; 1966.

90 ROSE, E.: Brit. Med. J., 1: 1258; 1952.

91 SCOTT, J.: Amer. J. Obstet. Gynec. 83: $185 ; 1962$.

92 SCHELPERT, J.: Amer. J. Obstet. Gynec. 76: $883 ; 1958$.

93 SCHIFFER, M. POMERANCE, W. \& MACKLES A.: Amer. J. Obstet. Gynec. 80: 516; 1960.

94 SCHLEGEL, R., New, r., LEAO, J., FARIAS, E., LEWCZAK, P. \& GARDNER, L.: Amer, J. Obstet. Gynec. 96: 357; 1966

95 SCHUMANN, E., \& VOEGELIN, A.: Amer. J. Obstet. Gynec. 33: 473; 1937.

96 SITARATNA, A., \& SARMA, V.: J. Obst. \& Gynec. Brit. Emp. 62: 301; 1960

97 SMITH, E. \& RUTEMBURG, A.: Amer. J. Obstet. Gynec. 96: 301; 1966.

98 SOBERON, A. Citado por Duarte A., Rolón R., y Palau, M.: Rev. Col. de Obs. y Gin. 6: $587 ; 1970$.

99 TAYLOR, J.: Brit. Med. J. 1: 1103; 1957

100 THIEDE, H. MORGAN, H.: Bull. Ass. franc., Cancer 50: 820; 1959.

101 TISNE, L., BARZELATTO, J., \& STEVENSON, C.: Boletín de la Sociedad Chilena de Cbstetricia y Ginecología. 20: 246; 1955. 
102 TOMINAGA, T. \& PAGE, E.: Amer. J. Obstet. Gynec. 96: 304; 1966.

103 TOW, S.: J. Obstet. Gynaec. Brit. Cwlth. $73: 544 ; 1966$.

104 TOW, S.: J. Obstet. Gynaec. Brit. Cwlth. 73 : $1000 ; 1966$.

105 TOW, S.: Aust. Z. J. Obstet. Gynaec. 5: $165 ; 1965$.

105 WAGNER, D., and RICHART, R.: Arch. Path. (Chicago) 85: 475; 1968.

107 VALENCIA, F., GONGORA, H., VELEZ, O., MEJIA, F., MEJIA, E.: Rev. Col. de Obs. y Gin. 15: 345; 1964.

108 WATERS, E., \& CRUDEN, A.: Amer. J. Obstet. Gynec. 46: 299; 1943.
109 VARGAS L., ONTIVEROS, E., PAVON, M., y McGREGOR, C.: Gin. y Obs. de México. 123: $515 ; 1966$.

110 VERgarA, R.: Rev. Col. de Obs. y Gin. 18: 165; 1967.

111 WEI, P. \& OUYANG, P.: Amer. J. Obstet. Gynec. 85: 844; 1963.

112 VILLAVICENCIO. Citado por Duarte, A., ROLON, R., y PALAU, M.: Rev. Col. de Obs. y Gin. 6: 587; 1970.

113 WILLIAMS, RUNYAN y HAGEN. Citados por J. G. C. C.: Progresos de Terapéutica Clínica. Vol. XXII. Fascículo 3: 714; 1969.

114 ZUSPAN, F.: Cls. Obs. y Gins. Dec.: 953; 1966. 